\title{
PRIMEIRO MOVIMENTO DO QUARTETO DE CORDAS N.3 DE HEITOR VILLA-LOBOS: UMA CORRESPONDÊNCIA DA FORMA SONATA CLÁSSICA NUMA CONJUNTURA ATONAL
}

\author{
Regina Rocha \\ Universidade de São Paulo \\ reginarocha@usp.br
}

\section{Resumo}

Este artigo apresenta apontamentos sobre uma possivel interpretação da forma sonata clássica, adaptada para um contexto atonal, no primeiro movimento do Quarteto de cordas n. 3 de Heitor Villa-Lobos. No âmbito da música brasileira, Villa-Lobos foi o compositor que mais escreveu quartetos de cordas. No cenário internacional da música do século XX, sua produção está em segundo lugar em termos quantitativos. Todavia, algumas análises mais antigas, com base apenas nos parâmetros da música tonal, defendem a ideia de que Villa-Lobos não utilizou a forma sonata em seus quartetos de cordas. No entanto, análises mais recentes demonstram a habilidade de Villa-Lobos em adaptar a forma sonata para um contexto não-tonal, assim como fizeram outros compositores vanguardistas. No caso do primeiro movimento do Quarteto de cordas n. 3, é possivel notar a manipulação das classes de alturas que demarcam as entradas das seções, em substituição às relações tonais da forma sonata clássica. Sendo assim, torna-se patente a proficiência composicional de Villa-Lobos, ao manusear um dos gêneros mais consagrados da música de câmara europeia (Quarteto de Cordas) e uma das estruturas formais mais significativas da música ocidental (Forma Sonata).

Palavras-chave: Villa-Lobos; Quartetos de cordas; Forma sonata; Música brasileira; Música de câmara. 


\section{Abstract}

This article presents comments on a possible interpretation of the classical sonata form adapted to an atonal context, in the first movement of The String Quartet No. 3 by Heitor Villa-Lobos. In the context of Brazilian music, Villa-Lobos was the composer who wrote string quartets the most. In the international music scene, his production is in second place, in quantitative terms. However, some older analyses, based only on tonal music parameters, defend the idea that Villa-Lobos did not use the sonata form in his string quartets. However, more recent analyses demonstrate Villa-Lobos' ability to adapt the sonata form to a non-tonal context, as did other avant-garde composers. In the case of the first movement of String Quartet n. 3, it is possible to notice the manipulation of the pitches that demarcate the entries of the sections, replacing the tonal relations of the classical sonata form. Thus, Villa-Lobos' compositional proficiency becomes evident, by handling one of the most established genres of European chamber music (String Quartet) and one of the most significant formal structures of Western music (Forma Sonata).

Keywords: Villa-Lobos; String Quartet; Sonata Form; Brazilian music; Chamber music. 


\section{Introdução}

De acordo com o musicólogo francês Bernard Fournier (1943-), o quarteto de cordas é o gênero da música de câmara que mais excedeu em quantidade e qualidade!. Fournier (2000) traduz em palavras 0 desafio colossal que esta modalidade musical requer aos compositores, visto que, segundo ele, "no quarteto de cordas o compositor está nu"

Sua economia, sua concentração não deixa espaço para facilidade ou efeitos; tem que ser capaz de dizer muito com poucos recursos sabendo que qualquer fraqueza é impiedosamente destacada por esse tipo de leitura analítica que dá à obra a necessária distribuição do discurso em quatro partes iguais e homogêneas: com o quarteto de cordas, o compositor está nu. [...] Ao contrário da sinfonia que the permite, por exemplo, tocar nas cores, nas escolhas da orquestração, o quarteto não the deixa possibilidade de diversão, estimula a sua verdadeira criatividade, que, não podendo ser exercido no sentido de uma busca de efeitos, deve centrar-se no trabalho de escrever em toda a sua pureza e precisão²... (FOURNIER, 2000, p. 12, tradução nossa, grifo nosso).

\footnotetext{
1 "Cela explique en partie l'importance exceptionnelle du répertoire pour quatuor à cordes avec une production qui dépasse en qualité et en quantité celle de tous les autres genres de musique de chambre" (FOURNIER, 2000, p. 11).

2 "Son économie, sa concentration ne laissent place ni à l'à-peu-près, ni à la facilité, ni aux effets; il faut être capable de beaucoup dire avec peu de moyens en sachant que toute faiblesse est impitoyablement mise en relief par cette sorte de lecture analytique que donne de l'oeuvre la nécessaire répartition du discours en quatre parties égales et homogènes: avec le quatuor à cordes, le compositeur-roi est nu. [...] À la différence de la symphonie qui lui permet, par exemple, de jover sur les couleurs, les choix d'orchestration, le quatuor ne lui laisse aucune possibilité de diversion, il stimule sa créativité vraie, qui, ne pouvant s'exercer dans le sens d'une recherche d'effets, doit se concentrer sur le travail de l'écriture dans toute sa pureté et sa précision, celle d'une épure" (FOURNIER, 2000, p. 12).
} 
Embora seu apogeu tenha sido no século XVIII, este gênero integra a obra de vários compositores ao longo da História da Música3', como podemos averiguar em alguns exemplos na tabela abaixo (Tabela 1):

\begin{tabular}{|c|c|c|c|c|c|c|}
\hline $\begin{array}{l}\text { Luigi Boccherini } \\
\text { (1743-1805) }\end{array}$ & & $\begin{array}{l}\text { Salvatore Sciarrino } \\
(1904-)\end{array}$ & \begin{tabular}{|l|l|} 
Henrique Oswald \\
$(1852-1931)$
\end{tabular} & & $\begin{array}{l}\text { Rachmaninoff } \\
(1873-1943)\end{array}$ & 2 \\
\hline $\begin{array}{l}\text { |gnas Pleyel } \\
(1757-1831)\end{array}$ & 70 & $\begin{array}{l}\text { Paul Hindemith } \\
(1895-1963)\end{array}$ & 7 György Ligeti & 4 & $\begin{array}{l}\text { Charles Ives } \\
(1874-1954)\end{array}$ & 2 \\
\hline $\begin{array}{l}\text { Joseph Haydn } \\
(1732-1809) \\
\end{array}$ & 68 & $\begin{array}{l}\text { Claudio Santoro } \\
\text { (1919-1989) }\end{array}$ & $\begin{array}{l}7 \text { Johannes Brahms } \\
(1833-1897)\end{array}$ & 3 & $\begin{array}{l}\text { César Guerra-Peixe } \\
\text { (1914-1993) }\end{array}$ & 2 \\
\hline $\begin{array}{l}\text { Anton Reicha } \\
(1770-1836) \\
\end{array}$ & 37 & $\begin{array}{l}\text { Béla Bartók } \\
(1881-1945)\end{array}$ & 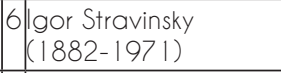 & 3 & $\begin{array}{l}\text { Carlos Comes } \\
(1836-1896)\end{array}$ & 1 \\
\hline $\begin{array}{l}\text { Amadeus Mozart } \\
(1756-1791)\end{array}$ & 23 & $\begin{array}{l}\text { Brian Ferneyhough } \\
\text { (1943-) }\end{array}$ & 6 Alberto Nepomuceno & 3 & $\begin{array}{l}\text { Claude Debussy } \\
(1862-1918)\end{array}$ & 1 \\
\hline $\begin{array}{l}\text { Darius Milhaud } \\
(1892-1974)\end{array}$ & 18 & $\begin{array}{l}\text { Piotr Tchaikovsky } \\
\text { (1840-1893) }\end{array}$ & \begin{tabular}{l|l} 
Camargo Guarnieri \\
(1907-1993)
\end{tabular} & 3 & $\begin{array}{l}\text { Maurice Ravel } \\
(1875-1937)\end{array}$ & 1 \\
\hline $\begin{array}{l}\text { Villa-Lobos } \\
(1887-1959) \\
\end{array}$ & & $\begin{array}{l}\text { Milton Babbitt } \\
(1916-2011)\end{array}$ & $\begin{array}{l}5 \begin{array}{l}\text { Camille Saint-Saëns } \\
(1835-1921)\end{array} \\
\end{array}$ & 2 & $\begin{array}{l}\text { Cesar Frank } \\
(1822-1890) \\
\end{array}$ & 1 \\
\hline $\begin{array}{l}\text { Ludwig Van Beethoven } \\
(1770-1827)\end{array}$ & 16 & $\begin{array}{l}\text { Elliott Carter } \\
(1908-2012)\end{array}$ & 5 Anton Webern & 2 & $\begin{array}{l}\text { Glauco Velasquez } \\
(1884-1914)\end{array}$ & 1 \\
\hline $\begin{array}{l}\text { Franz Schubert } \\
(1797-1828) \\
\end{array}$ & 15 & $\begin{array}{l}\text { Giacinto Scelsi } \\
\text { (1905-1988) }\end{array}$ & \begin{tabular}{|l|l|}
5 Dmitry Kabalevsky \\
$(1904-1987)$
\end{tabular} & 2 & $\begin{array}{l}\text { Osvaldo Lacerda } \\
(1927-2011)\end{array}$ & 1 \\
\hline $\begin{array}{l}\text { Dmitry Shostakovitch } \\
(1906-1975)\end{array}$ & 15 & $\begin{array}{l}\text { Arnold Schoenberg } \\
(1874-1951)\end{array}$ & \begin{tabular}{|c|l}
5 & $\begin{array}{l}\text { Serguei Prokofiev } \\
(1954-2014)\end{array}$ \\
\end{tabular} & 2 & $\begin{array}{l}\text { Alexandre Levy } \\
\text { (1864-1892) }\end{array}$ & 1 \\
\hline $\begin{array}{l}\text { Antonin Dvorak } \\
(1841-1949)\end{array}$ & 14 & $\begin{array}{l}\text { Alfred Schnittke } \\
\text { (1934-1998) }\end{array}$ & $\begin{array}{l}4 \mid \begin{array}{l}\text { Francisco Mignone } \\
(1897-1986)\end{array} \\
\end{array}$ & 2 & $\begin{array}{l}\text { Samuel Barber } \\
(1910-1981)\end{array}$ & 1 \\
\hline
\end{tabular}

Tabela 1: Alguns compositores que escreveram para o gênero quarteto de cordas entre os séculos XVIII e XX.

Fonte: a autora.

3 "Em nenhum momento de sua história, o quarteto de cordas deixou de ser considerado pela maioria dos compositores, mesmo às vezes por aqueles que não o abordaram (Liszt) ou apenas tocaram nele, como o gênero em que expressa a suprema conquista da "profissão" de um compositor" (FOURNIER, 2000, p. 12). "À aucun moment de son histoire le quatuor à cordes n'a cessé d'être considéré par la plupart des compositeurs, même parfois ceux qui ne l'ont pas abordé (Liszt) ou ne l'ont qu'effleuré, comme le genre où s'exprime l'achèvement suprême du "métier » de compositeur" Fournier (2000) menciona que no período romântico e pós-romântico, apenas grandes pianistas e sinfonistas, tais como Chopin e Liszt, Berlioz e Mahler não elaboraram composições para quartetos de cordas. "[...] quanto a Liszt, foi ele quem aconselhou Brahms a escrever quartetos". "Dans les périodes et romantiques et postromantiques par exemple, on ne peut guère citer que de grands pianistes, Chopin ou Liszt, et de grands symphonistes, Berlioz ou Mahler, qui n'aient pas composés de quatuors, ces deux derniers ayant d'ailleurs néanmoins témoigné de leur intérêt pou le genre, l'un dans ses écrits (commentaires admiratifs des derniers quatuors de Beethoven dans les Mémoires), l'autre par ses transcriptions; quant à Liszt, c'est lui qui conseilla à Brahms d'écrire des quatuors" (FOURNIER, 2000, p. 1 I).

\section{2}

REV. TULHA, RIBEIRÃO PRETO, v. 6, n. 2, pp. 119-151, jul.-dez. 2020 
No que concerne à música brasileira, a partir da observação da tabela acima, é possivel constatar que nenhum outro compositor brasileiro, mesmo com formação musical na Europa, tal como: Alexandre Levy (1864-1892), Carlos Comes (1836-1896) e Alberto Nepomuceno (1864-1920), escreveu a quantidade de quartetos de cordas que Villa-Lobos produziu. Já no cenário internacional da música do século $X X$, em termos quantitativos, Villa-Lobos só está abaixo do compositor francês Darius Milhaud (1892-1974), por um único número4. Este fato evidencia a proficiência composicional de Villa-Lobos's, que, além de ser "o compositor das Bachianas e dos Choros", não se intimidou diante da preeminência do gênero do classicismo musical europeu (quarteto de cordas).

De acordo com Fournier (2000), o quarteto de cordas foi o gênero predileto no que tange ao emprego da forma sonata:

Afirmando-se muito rapidamente como um dos gêneros emblemáticos do classicismo, o quarteto, ainda mais do que a sinfonia, provou, graças a Haydn, o lugar das experiências formais mais fecundas; a forma sonata, recentemente entronizada no universo das formas musicais, encontrou ali sua terra eleita 7 (FOURNIER, 2000, p. 11, tradução nossa) ${ }^{8}$.

4 Villa-Lobos iniciou o ciclo de quartetos de cordas em 1915, aos 28 anos de idade, e este ciclo perdurou até 1957, dois anos antes de sua morte. Foram 17 composições neste gênero e no cenário da música do século XX, esta quantidade só está abaixo da do compositor francês Darius Milhaud, que compôs 18 quartetos de cordas.

5 Roussel afirmou que o gênero quarteto de cordas é o "teste por excelência, que revela, sem aparelhamento e sem maquiagem, o valor do músico, a qualidade da música que ele carrega". "[...] comme l'a dit Roussel de «l'épreuve par excellence, qui révèle, sans truquages et sans fards, la valeur du musicien, la qualité de la musique qu'il porte en lui" (FOURNIER, 2000, p. 12)

6 De acordo com o musicólogo finlandês Eero Tarasti (1948-), grande parte da notoriedade internacional de Villa-Lobos está respaldada na Série Choros e na Série Bachianas Brasileiras: "Altogether there are nine bachianas and, like the choros, they have been scored for varied mediums. It is on these two series that Villa-Lobos's international reputation is largely based" (TARASTI, 1995, p. 181).

7 "S'affirmant très vite comme un des genres emblématiques du classicisme, le quatuor, plus encore que la symphonie, se révéla grâce à Haydn le lieu des expériences formelles les plus fécondes; la forme sonate, nouvellement intronisée dans l'univers des formes musicales, trouva là sa terre d'élection" (FOURNIER, 2000, p. I I).

$8 \bigcirc$ musicólogo francês Roland de Candè (1923-2013) também destaca o papel de Haydn na evolução do quarteto de cordas: "Haydn proporcionou o modelo perfeito da sinfonia e da sonata para piano clássicas. Mas é no quarteto de cordas que se revela plenamente seu gênio. Ele não 'inventou' o gênero, mas levou-o a uma perfeição de que seus predecessores não se aproximaram" (CANDË, 1994, p. 612).

\section{3}

REV. TULHA, RIBEIRÃO PRETO, v. 6, n. 2, pp. 119-151, jul.-dez. 2020 
Antes de entrarmos na análise do quarteto em questão, vamos fazer uma breve reflexão sobre a forma sonata, que é uma das estruturas formais de maior relevância da música instrumental europeia.

A forma sonata9 foi uma grande revolução no universo musical, pois possibilitou a emancipação da música instrumental, que, há séculos, estava vinculada à palavra ${ }^{10}$. Esta nova práxis foi aplicada numa extensa possibilidade de formação instrumental, tais como: sinfonias, concertos, trios, sonatas para instrumentos solos e quartetos de cordas.

\section{- compositor americano Douglas Moore (1893-1969) conceitua} a forma sonata como "a grande obra arquitetônica do Classicismo musical" (MOORE, 200 l, p. 80). Já os musicólogos franceses Jean Massin (1917-1986) e Brigitte Massin (1927-2002) consideram a forma sonata como a estrutura central da música ocidental, desde a Primeira até a Segunda Escola de Viena (J. MASSIN; B. MASSIN, 1997, p. 548). Vejamos um exemplo da utilização da forma sonata numa obra de Schoenberg (1874-1951). De acordo com o compositor americano Ceorge

9 Para o início desta discussão, é importante salientar a diferença entre sonata e forma sonata. De acordo com o musicólogo Douglas Green (1926-1999) "a forma sonata é uma forma que no percurso da história exerceu um papel tão importante nos vários movimentos da sonata que o nome foi associado a ela" (CREEN, 1979, p. 182). Já o termo sonata tem origem no latim sonare (soar) e indica ser uma composição designada para música instrumental, ou seja, o título demarca que a execução não é vocal, como no caso da cantata. Via de regra, o primeiro movimento das sonatas tinha uma organização estrutural em três partes, na qual posteriormente foi denominada de forma sonata. De acordo com Charles Rosen (1927-2012), foi o compositor alemão Adolph Bernhard Marx (1795-1866) quem batizou o termo forma sonata em Die Lehre von der musikalischen Komposition - III volume (1845). No entanto, Rosen (1998, p. 3, 15) cita outros registros pioneiros que descreveram o gênero. São eles: La Scuola della Musica (1800) de Carlo Gervasoni (1762-1819); Traité de haute composition musicale - II volume (1826) de Antonin Reicha (1770-1836) e School of Practical Composition (1848) de Carl Czerny (1791-1857). No relato dos musicólogos Jean e Brigitte Massin (1997, p. 549), encontra-se a informação de um registro ainda mais antigo, que descreve a forma sonata, porém sem designar o termo. Trata-se do Versuch einer Anleitung zur Composition (1782-1793) de Heinrich Koch (1749-1826). Hepokoski e Darcy (2006, p. 14) comentam que Haydn (1732- 1809), Mozart (1756-1791) e Beethoven (1770-1827) desconheciam esta terminologia. Green (1979, p. 178) comenta que "a história da sonata é complexa, pois a História do termo não coincide com a História do gênero".

10 Um exemplo da ancestralidade dessa subordinação da música ao texto pode ser observado no comentário do filósofo alemão Georg Hegel (1770-1831): "A tragédia antiga já era musical, mas a música não desempenhava nela papel dominante, pois nas obras poéticas propriamente ditas o primeiro lugar pertence à expressão verbal das ideias e dos sentimentos, e a música que atingira entre os antigos o grande desenvolvimento melódico e harmônico da música da época cristã não podia servir senão para animar, ritmando-as, as palavras poéticas, para assim as tornar mais acessiveis ao sentimento" (HECEL, 2010, pp. 349-350).

\section{4}

REV. TULHA, RIBEIRÃO PRETO, v. 6, n. 2, pp. 119-151, jul.-dez. 2020 
Perle (1915-2009), no Klavierstück opus 33a, Schoenberg realiza as demarcações das seções, por meio da manipulação do conjunto em diferentes tipos de segmentação da série ${ }^{\prime}$. $\bigcirc$ musicólogo britânico Nicholas Cook (1950-), ao analisar esta mesma obra (Klavierstück opus 33a), também faz uma analogia da organização tonal da forma sonata com o gerenciamento das transposições dos conjuntos ${ }^{12}$. Ponderamos como vital este olhar analítico que considera a transmutação da forma sonata clássica, fundamentada nas relações tonais, para uma adaptação desta estrutura num discurso não tonal. Ao refletirmos sobre esta questão, fazemos uma relação com a Filosofia da Ciência por intermédio do pensamento do físico e pesquisador americano Thomas Samuel Kuhn (1922-1996) que considera os "desvios das normas" eventos aparentemente estranhos dentro de um determinado sistema -, um fator essencial no desenvolvimento de novas conquistas científicas. conceito de "revolução científica" defendido por Kuhn (2006, p. 24-25) de alguma forma equivale ao uso de ferramentas pós-tonais aplicadas em obras de Villa-Lobos, tal como vem ocorrendo desde as últimas duas décadas. No entanto, a falta desta compreensão produz afirmações errôneas. No caso dos quartetos de Villa-Lobos, vejamos algumas conclusões equivocadas, que não consideram a possibilidade de uma reinterpretação da forma sonata para o século XX.

O pianista brasileiro Arnaldo Estrella (1908-1980), ao escrever um livro, em 1970, sobre os Quartetos de Cordas de Villa-Lobos, afirma que não existe a forma sonata nos quartetos de Villa-Lobos: "[...] $\bigcirc$ mesmo não acontece com a forma sonata. Nos seus quartetos, Villa-Lobos não a utiliza, não procura utilizá-la. Ignora-a completamente. $\bigcirc$ molde não the convinha, não o seduz ${ }^{3 "}$ (ESTRELLA, 1970, p.11). Apesar do trabalho de Estrella (1970) ser apreciável, esta negação contundente de que Villa-Lobos não utilizou a forma sonata em seus quartetos não

11 "The formal subdivisions of Opus 33a are clarified through the subjection of the set to diferente types of segmentation" (PERLE, 1991, p. 113)

12 "The transpositions within which the P-O/l-5 combined set appears are also associated with the sonata form, although they are not quite equivalente to the traditional tonal plan since the first transpossition occurs near the beginning of the development na not with the second subject; this might be better regarded as na attempt to recreate the tensional arch-shape typical of a sonata rather than as a direct substitute for tonal relations" (COOK, 2009, p. 328).

13 Conforme pode ser atestado no relato de Salles (2017c, p. 420), a pesquisadora Lisa Peppercorn também nega a presença da forma sonata nos quartetos de Villa-Lobos. Para ela, Villa-Lobos era desprovido de conhecimento técnico para ter êxito no manuseio da forma sonata. Consideramos que este julgamento é mais um modelo analítico obsoleto que não pondera as mudanças de paradigmas da música do século XX. 
reflete os resultados das pesquisas mais recentes sobre o assunto. Pelo fato de a musicologia brasileira ter avançado no desenvolvimento da análise, já é possivel ter uma outra compreensão em várias obras de Villa-Lobos, das quais anteriormente ficavam com "pendências" ao não se encaixarem dentro das regras da tonalidade. Alguns exemplos destes trabalhos são: a série Choros (ALBUQUERQUE, 2014, 2018), Estudos para Violão (VISCONTI, 2016), e a série Quartetos de Cordas (SALLES'4, 2008, 2012a, 2012b, 2017a, 2017b, 2017c, 2018). A seguir, veremos a constatação de Salles quanto à estrutura dos 17 quartetos de cordas de Villa-Lobos:

Dentre os dezessete quartetos de corda de Villa-Lobos, quinze deles têm pelo menos um movimento estruturado em forma de sonata, dialogando com as tradições clássica e/ou romântica - manifestando graus variados de intertextualidade com obras de Haydn, Beethoven, Franck e d'Indy. Nesses quartetos Villa-Lobos reinterpreta a dicotomia tonal entre tônica e dominante através de sua linguagem harmônica peculiar, com elementos póstonais relacionados com unidades formais como: tema (ou grupo de temas) principal e secundário; transições e desenvolvimentos; exposição e recapitulação, etc (SALLES, 2017 c, p. 4 19).

Outra constatação do uso da forma sonata nos quartetos de Villa-Lobos é a do musicólogo americano Hans Tischler (1915-2010):

oitavo Quarteto de Cordas (em Dó) de Heitor VillaLobos, escrito no Rio de Janeiro em 1944 e dedicado ao Quarteto lacovino, foi tocado no concerto inicial de 16 de novembro. Trata-se de uma grande da literatura

14 Paulo de Tarso Salles é professor livre docente da Escola de Comunicação e Artes da Universidade de São Paulo e fundador do grupo de pesquisa PAMVILLA (Perspectivas Analíticas para a Música de Villa-Lobos). Desde 2003 Salles tem desenvolvido pesquisas no campo da Teoria e Análise Musical sobre a obra de Villa-Lobos. Como parte desta pesquisa analisou os 17 Quartetos de Cordas de Villa-Lobos. Um dos resultados deste trabalho foi o lançamento do livro: Os quartetos de cordas de Villa-Lobos: forma e função, que é a produção mais completa deste assunto. Neste livro Salles analisa com riqueza de detalhes cada um dos 17 quartetos, demonstrando os diálogos estéticos com outros compositores e a personalidade composicional sui generis de Villa-Lobos. Cf.: Salles (20|8). 
contemporânea de música de câmara, é difícil entender por que tivemos de aguardar cinco anos pela sua primeira apresentação neste país.

Com relação à forma, a obra é conservadora, construída em clara forma sonata, um segundo movimento em forma canção, com seção intermediária, um movimentado scherzo no qual a primeira parte é repetida após um trio de caráter folclórico, e uma forma sonata mais complexa, com elementos de rondó, como conclusão. Não obstante o uso dessas formas clássicas, seria errôneo acusá-lo de "formalismo"; o material é desenvolvido com habilidade e imaginação, e com completa liberdade e lógica (TISCHLER apud SALLES, 2018, p. 45, grifo nosso).

É a partir desta perspectiva que se interpreta a forma sonata clássica na conjuntura da música do século XX, por meio de ferramentas analíticas não-tonais, por que serão realizados alguns apontamentos de uma possivel interpretação da organização estrutural do primeiro movimento do Quarteto de cordas n. 3 de Heitor Villa-Lobos.

\section{Estrutura formal}

primeiro movimento do Quarteto de cordas n. 3 de Villa-Lobos é classificado por Salles (2017a, p. 70) como uma sonata tipo 3, com base na tipologia' ${ }^{15}$ de Hepokosky e Darcy (2006), e como uma forma sonata cíclica ${ }^{16}$, ou seja, os temas contidos no primeiro movimento estão presentes nos demais movimentos desta peçal'.

15 Hepokosky e Darcy (2006) classificam a forma sonata em cinco diferentes tipos: tipo I (sem desenvolvimento), tipo 2 (a recapitulação ocorre somente a partir do grupo de temas secundários e pode não ocorrer a recapitulação), tipo 3 (exposição, desenvolvimento e recapitulação), tipo 4 (sonata rondó, com a ausência do desenvolvimento), tipo 5 (concerto, via de regra, na exposição os temas são expostos inicialmente pela orquestra e permanecem na tônica. Apenas na entrada dos solistas é que os temas saem da tônica ainda na exposição).

16 Salles (2017a) classifica os Quartetos de Cordas de Villa-Lobos em seis grupos: I. Aforístico, 2. Cíclicos, 3. Rapsódico, 4. Haydiniano, 5. "Expressionista", 6. Estilo maduro. Cf.: Salles (2017a, p. 71)

17 Embora este artigo aborde apenas o primeiro movimento do quarteto em questão, os temas serão denominados de temas cíclicos. 
Este movimento possui três temas que conduzem o discurso musical reiterados de forma literal ou com variações. Os temas cíclicos (a) e (b) são expostos logo nos primeiros dez compassos. Entre os compassos 1 e 4 encontramos o tema cíclico (a), com uma textura homofônica, na região médio grave. Conectado à última nota deste tema (compasso 4), surge o tema cíclico (b), com uma textura polifônica, numa região mais aguda do que o tema anterior. No compasso 6 de forma muito sutil (violino II), surge um fragmento motívico, que é um preâmbulo do tema cíclico (c) que surgira na seção seguinte (Figura 1).

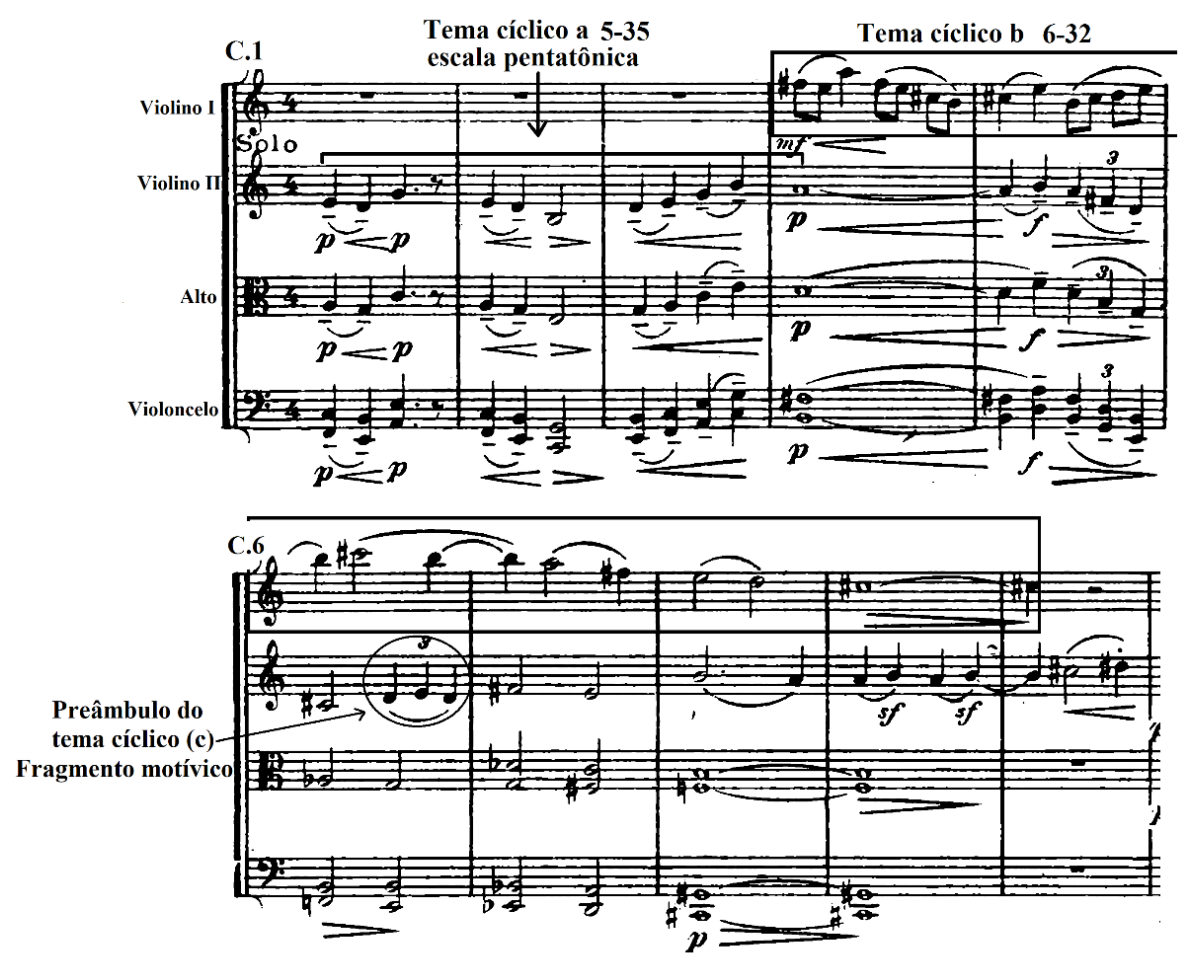

Figura 1: Quarteto de Cordas n. 3 de Villa-Lobos. Exposição.

Tema cíclico a (compassos l a 4). Tema cíclico b (compassos 4 al0).

Entre estes dois temas, há algo interessante. $\bigcirc$ tema cíclico (b) é derivado do tema cíclico (a). As cinco primeiras notas possuem os 
mesmos intervalos e pertencem ao conjunto de classe de alturas ${ }^{18} 4-26$ (Figura 2).

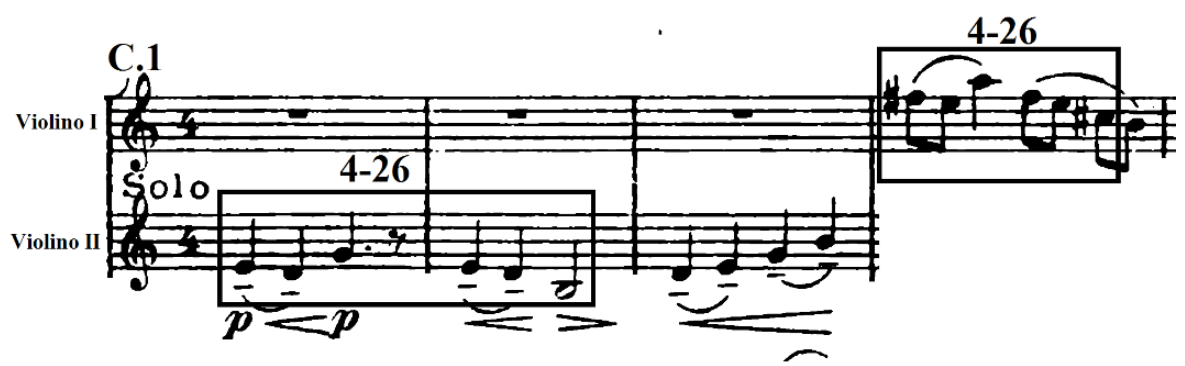

Figura 2: Quarteto de Cordas n. 3 de Villa-Lobos. Exposição.

Primeiras quatro notas do tema cíclico (a) e (b) que pertencem ao CCA 4-26.

Sendo assim, o tema cíclico (b) poderia ser interpretado como parte do tema cíclico (a). No entanto, consideramos os compassos I a 10 como dois temas distintos, pois na Exposição o tema cíclico (a) permanece sempre inserido no CCA 5-35 (escala pentatônica), ao contrário do tema cíclico (b) que surge com o CCA 6-32 e no decorrer da exposição surge em outros referenciais escalares. Outro aspecto que reforça a ideia de dois temas é a diferença de textura já citada (Figura 1).

No compasso 11, o tema cíclico (b) surge no violoncelo, ou seja, num instrumento de sonoridade bem mais grave em relação à primeira eclosão que foi no violino I no compasso 4 (Figura 1). Este processo oferece um jogo de cores sonoras logo no início da exposição. $O$ referencial escalar muda para o CCA 7-23, pois a penúltima nota desliza um semitom abaixo (Figura 3).

No compasso 13, de forma imbricada, o tema cíclico (b) é apresentado pela viola e é formado pela escala diatônica CCA 7-35 (Figura 3).

18 Neste artigo, para identificar o conjunto de classe de alturas, será adotada a sigla CCA. 


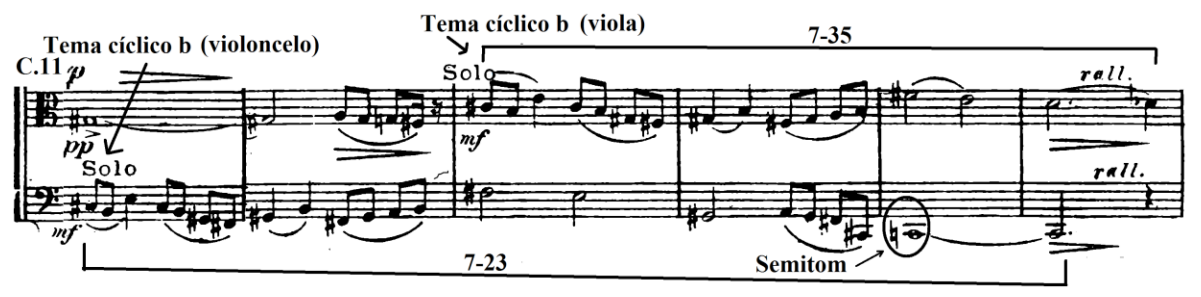

Figura 3: Quarteto de Cordas n. 3 de Villa-Lobos. Exposição.

Tema cíclico (b) no violoncelo (compasso l l) e na viola (compasso 13).

Obs.: os demais instrumentos foram omitidos.

Quanto a esta sobreposição, há uma ocorrência semelhante atestada por Salles (2012, p. 29), no primeiro movimento do Quarteto de cordas n. 2 de Villa-Lobos (Figura 4). Entre os compassos 5, 6 e 7, o tema (a) transforma-se em um contraponto do tema (b), por estarem sobrepostos com uma pequena defasagem de tempo (Figura 4).

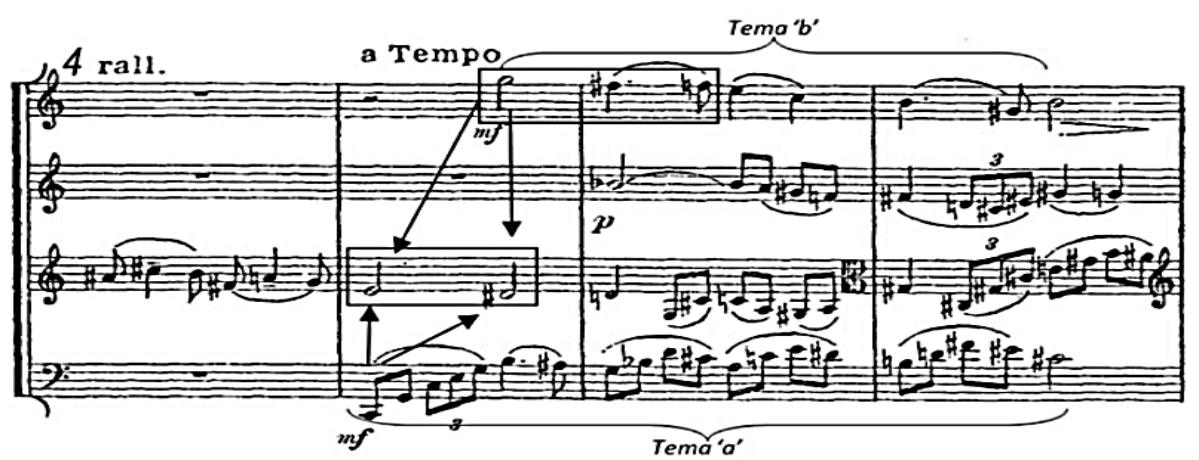

Figura 4: Quarteto de Cordas n. 2 de Villa-Lobos. I Movimento (compassos 4 a 7).

Fonte: SALLES (2012b, p. 29)

Este fato, presente tanto no Quarteto de Cordas n. 2 como no Quarteto de Cordas n. 3 de Villa-Lobos, interpretamos como um procedimento semelhante ao que ocorre no primeiro movimento do Quarteto de Cordas op. 33 n. $1^{19}$ de Haydn, do qual o musicólogo Charles

$19 \bigcirc$ conjunto de quartetos de cordas opus 33 de Haydn, também conhecido como quartetos scherzi ou russos, foi escrito em 1781 e compreende seis quartetos. - "... escritos 'numa maneira inteiramente nova e especial' são um momento culminante no domínio do desenvolvimento temático" (LOVELOCK, 2013, p. 181). 
Rosen (1927 - 2012) denomina como a "invenção do contraponto clássico" (Figura 5).

Ninguém pode dizer exatamente em que ponto nos compassos 3 e 4 o violino deve ser julgado como a principal voz melódica, e onde o violoncelo muda para uma posição subordinada, já que a passagem não é divisível. Tudo o que se sabe é que o violino começa no compasso 3 como acompanhamento e termina no compasso 4 como melodia.

Esta é a verdadeira invenção do contraponto clássico. Não representa de forma alguma um renascimento da técnica barroca, onde o ideal (nunca, é claro, a realidade) era a igualdade e a independência das vozes. [...] $\bigcirc$ contraponto clássico geralmente abandona até mesmo a pretensão de igualdade. A página de abertura deste quarteto, por exemplo, afirma a distinção entre melodia e acompanhamento. Mas então transforma um no outro (ROSEN, 1998, p. 116-117).

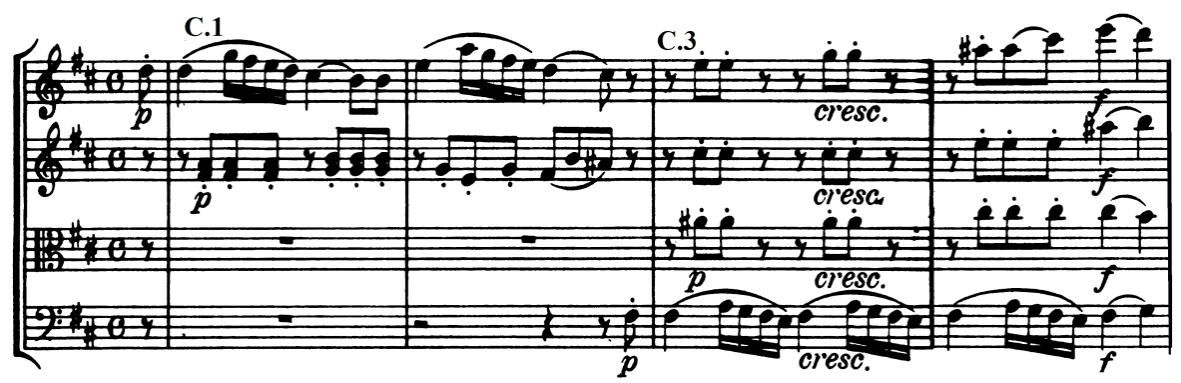

Figura 5: Quarteto op. 33 n.I de Haydn - I movimento. Compassos I a 4.

Retornando à análise do Quarteto de cordas n. 3 de Villa-Lobos (Figura 6), entre os compassos 17 e 20, o tema cíclico (a) reaparece na escala pentatônica CCA 5-35, seguido de uma variação do tema cíclico (b) no violoncelo com o CCA 7-27 (compassos 20 a 22).

No compasso 22, o prenúncio do tema cíclico (c) reaparece, porém com mais ênfase, pois agora está posicionado no violino I.

Entre a segunda parte do compasso 24 até o compasso 29 há uma transição que conduz o discurso musical para a seção B (Figura 6). 
Tema cíclico (a) 5-35

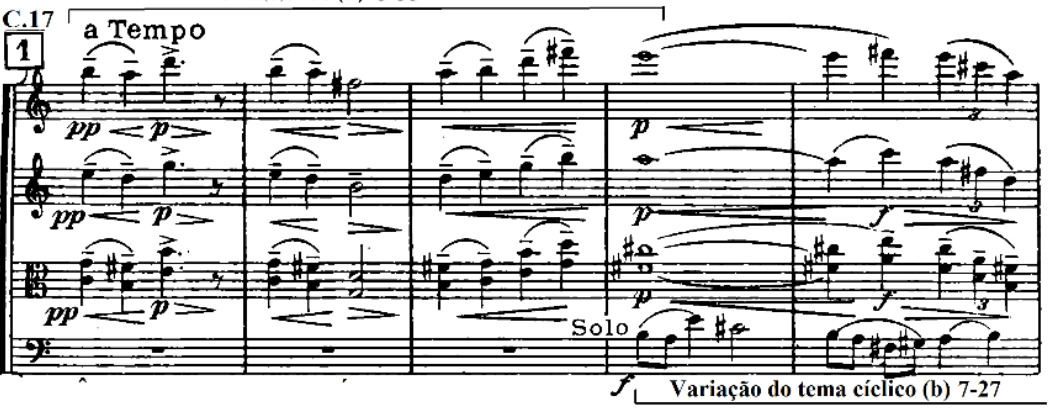

Preâmbulo do tema cíclico (c)
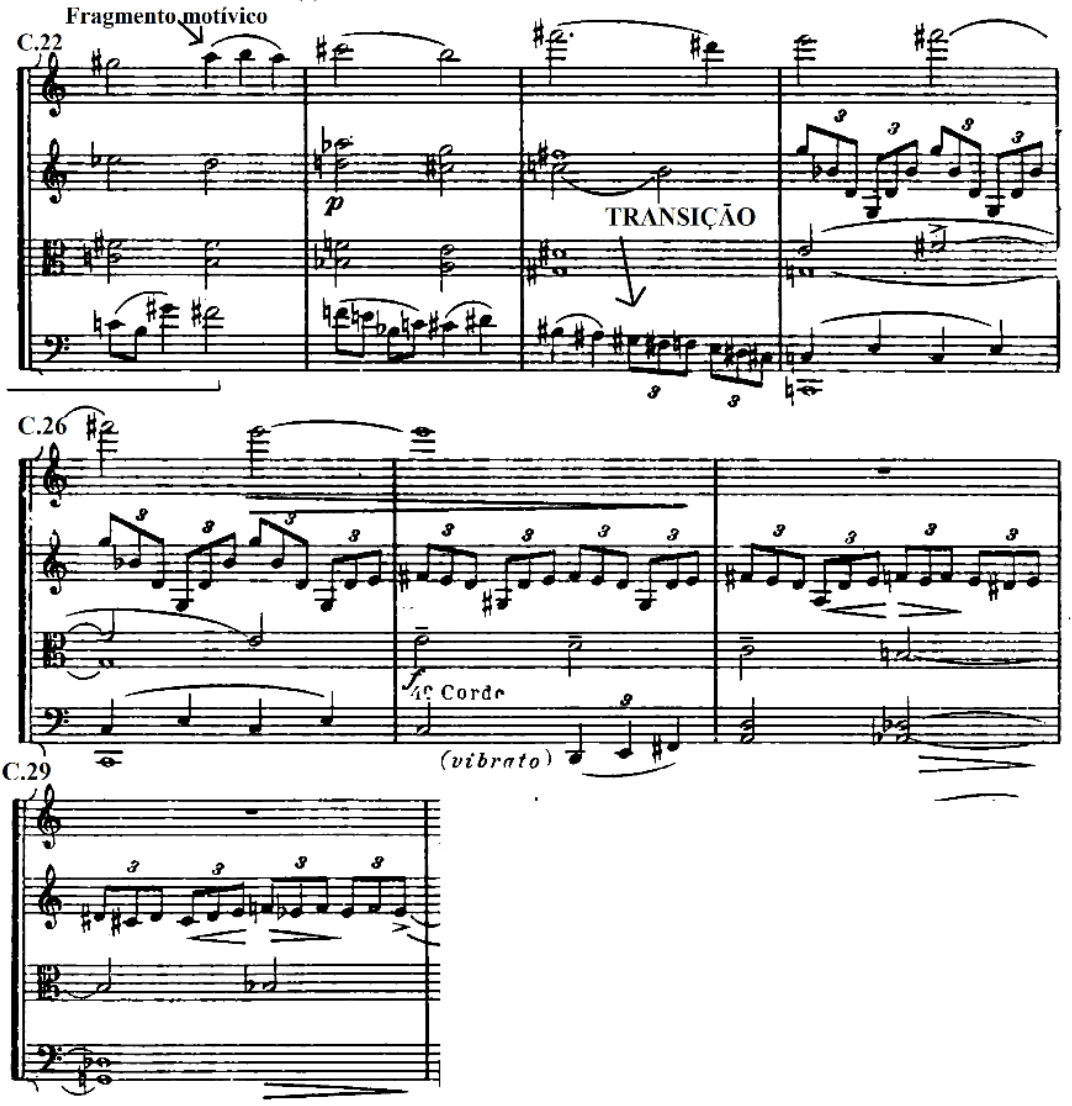

Figura 6: Quarteto de Cordas n. 3 de Villa-Lobos. Exposição. Tema cíclico a (compassos 17 a 20) CCA 5-35.

Tema cíclico b (compassos 20 a 24) CCA 7-27. Transição (compassos 24 a 29). 
A seção B (Desenvolvimento) traz um procedimento alusivo à seção de desenvolvimento da forma sonata clássica. Villa-Lobos insere o tema cíclico (a) num referencial escalar distinto da seção A. Isto pode sugerir uma sensação auditiva de modulação, pois, na Exposição, este tema estava sempre inserido na escala pentatônica (CCA 5-35). Na entrada da seção $B$, o tema cíclico (a) sofre a primeira mudança no CCA e aparece com o CCA 7-27 (Figura 7), que é o mesmo conjunto da última ocorrência do tema cíclico (b) (compassos 20 a 22) na seção anterior (Figura 6). Contudo, o tema cíclico (b) tem o seu debute no desenvolvimento com as primeiras seis notas do tema cíclico (a) na exposição: Mi-Ré-Sol-Mi-Ré-Si. Assim sendo, o desenvolvimento é inaugurado pela técnica da inversão dos referenciais escalares.

\section{SEÇ̃̃O B}

Tema cíclico a (violino I)

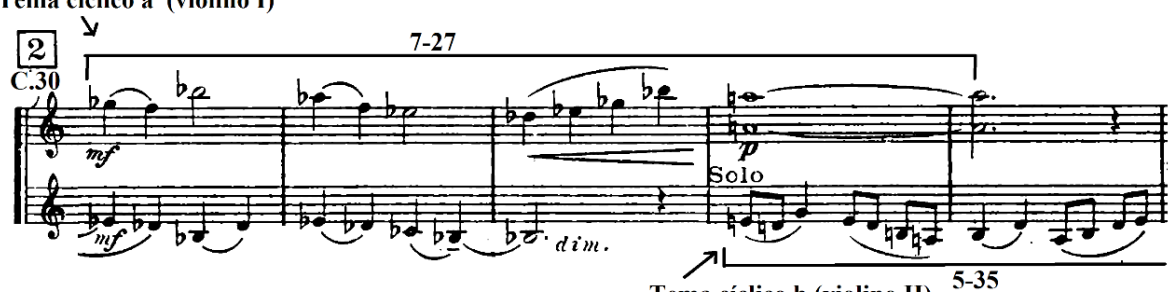

Tema cíclico b (violino II)

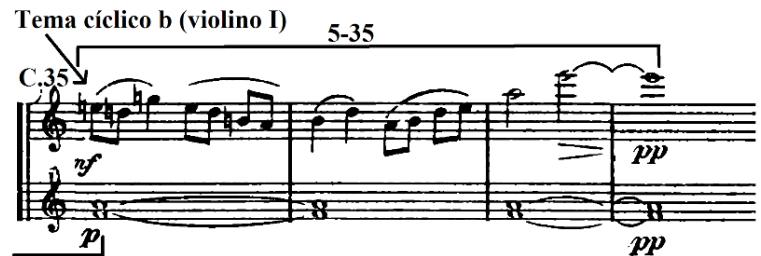

SEÇÃO A

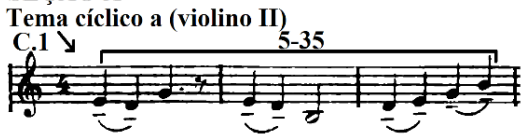

Figura 7: Quarteto de Cordas n. 3 de Villa-Lobos. Desenvolvimento. Inversão do CCA dos temas cíclicos (a) e (b) em relação à Seção $A$.

Logo após (c. 38-4 I), mantendo o mesmo CCA 5-35, observa-se uma variação do tema cíclico (b) por meio da mudança de articulação (de legato para staccato) e de uma pequena diferença rítmica e intervalar (Figura 8). 
Violoncelo

$5-35$

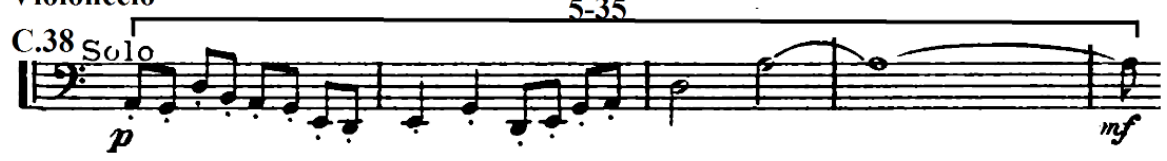

Figura 8: Quarteto de Cordas n. 3 de Villa-Lobos. Desenvolvimento. Variação do tema cíclico b (compassos 38 a 41 ).

Na sequência, constata-se outra variação do tema cíclico (b) que será denominado de tema b. l, pois, diferente da variação anterior (compassos 38 a 4 l), não é uma ocorrência isolada. Ela surge entre os compassos 41 e 48 (violino I) e de imediato segue para o violino II (compassos 49 a 53) (Figura 9).

\section{Tema b.1 (violino I)}
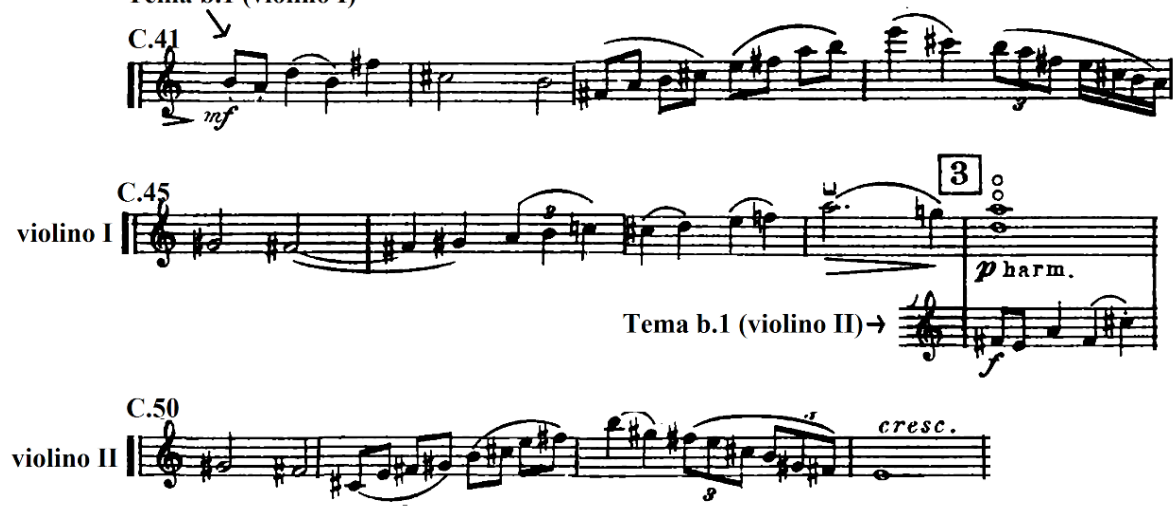

Figura 9: Quarteto de Cordas n. 3 de Villa-Lobos. Desenvolvimento.

Tema b. I = violino I (compassos 4 l a 49) e violino II (compassos 49 a 52).

A partir do compasso 50 temos o tema cíclico (c). Este tema é construído de forma distinta dos demais, pois ele vai sendo propagado de forma paulatina. Na Exposição (compasso 22), houve um inciso motívico deste tema e a primeira manifestação com o motivo completo ocorre no compasso 50 na viola (Figura 10). 

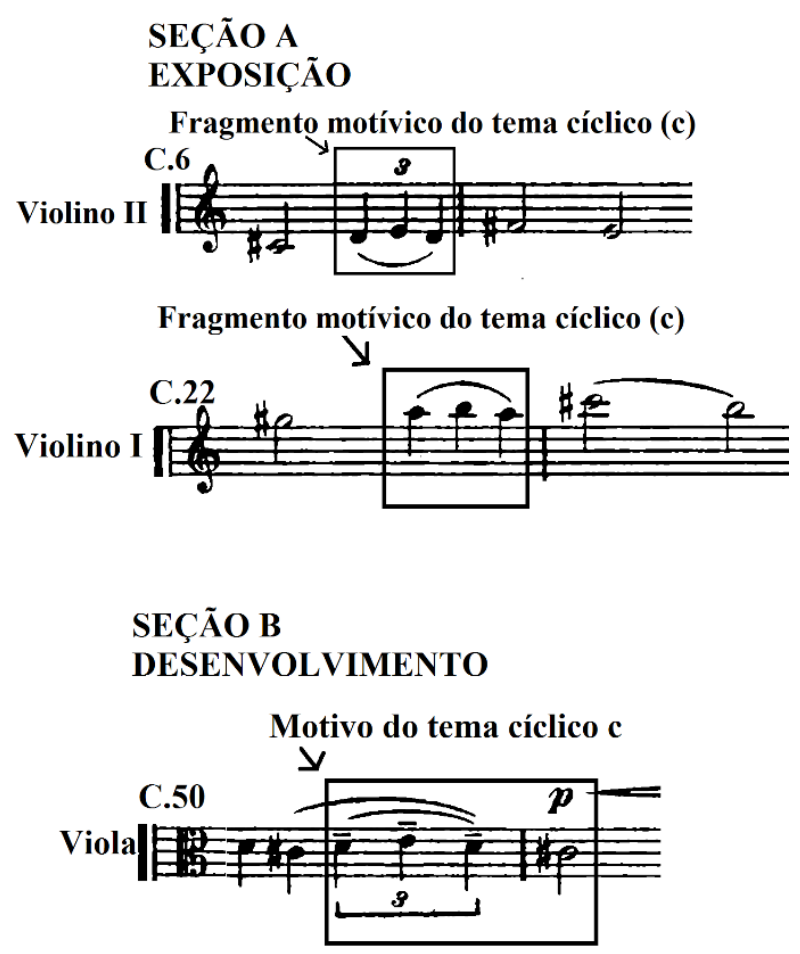

Figura 10: Quarteto de Cordas n. 3 de Villa-Lobos. Tema cíclico c na exposição e desenvolvimento.

A partir do compasso 50, o tema cíclico (c) aparece na íntegra seguido de variações até o compasso 82. Entre os compassos 51 e 55, há uma espécie de contraponto temático entre o tema cíclico (c) e o tema cíclico (a) no violoncelo (Figura 11). 

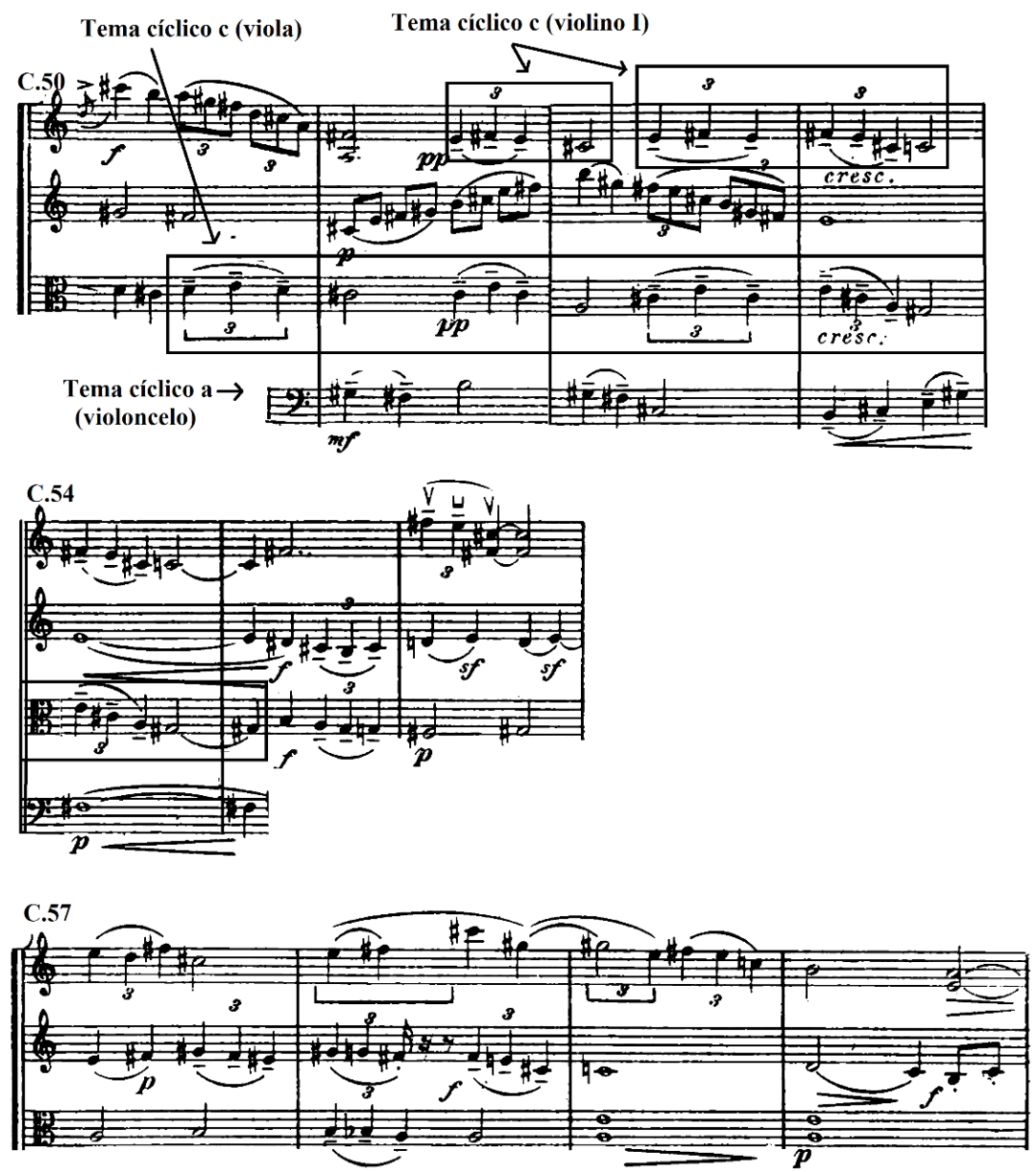

Tema cíclico c (violino I)

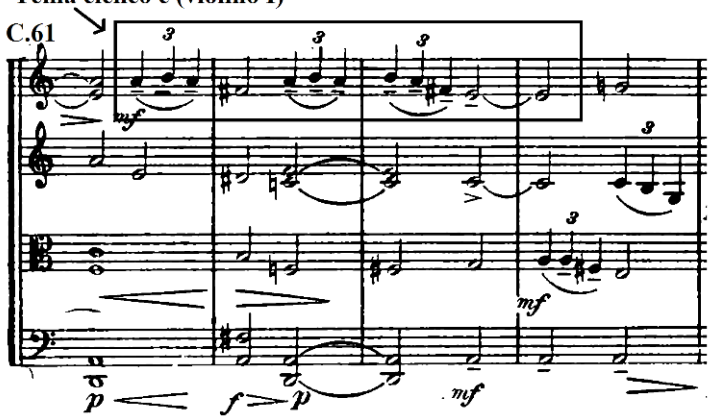

Figura 1 1: Quarteto de Cordas n. 3 de Villa-Lobos. Desenvolvimento. Tema cíclico (c). 
Entre os compassos 73 e 78, o tema cíclico (c) apresenta-se com uma figuração de maior valor (mínimas) em relação às exibições anteriores (semínimas, Figura 11 ). Este procedimento estimula a impressão de que andamento ficou mais lento. E este fato, somado à rarefação entre os compassos 79 e 82, sugere a pontuação do término da primeira seção do desenvolvimento, pois a seguir teremos os mesmos temas dispostos em outras texturas.

No compasso 82, surge um fragmento do tema cíclico (a) no violoncelo, seguido de uma pausa e com a utilização de harmônicos. Desse modo, Villa-Lobos prepara o ouvinte para a sonoridade da próxima subseção (Figura 12).

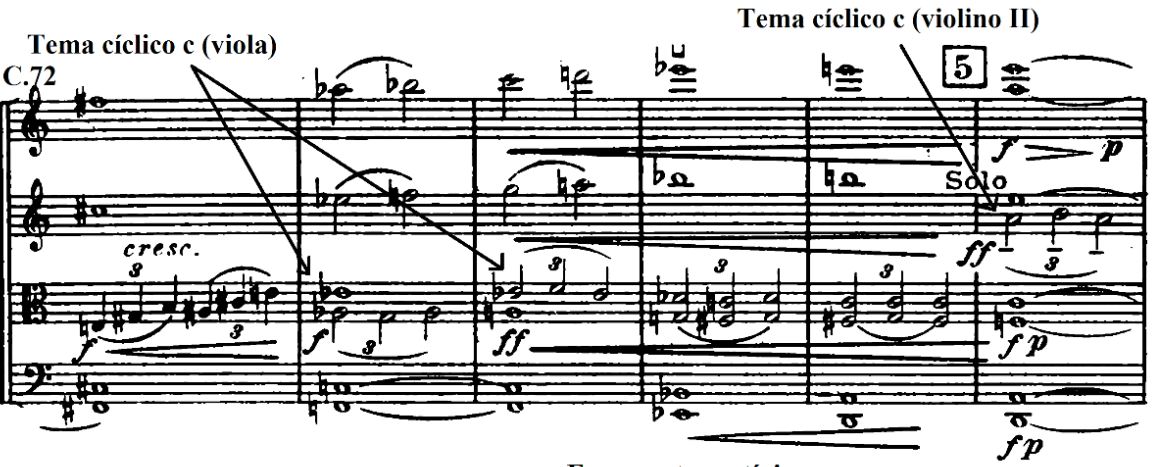

Tema cíclico c (viola)

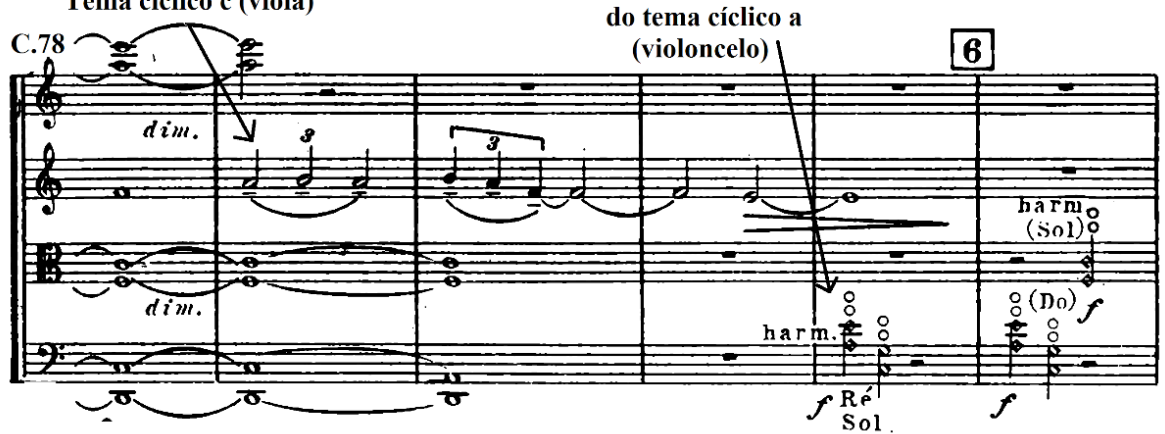

Figura 12: Quarteto de Cordas n. 3 de Villa-Lobos. Desenvolvimento. Tema cíclico c.

A partir do compasso 83 a nova subseção do desenvolvimento nasce com o tema cíclico (a) disposto entre diferentes vozes20 (Figura 13).

20 Tanto Estrella (1970) como Salles (2017) comentam que, em certos momentos, Villa-Lobos dispõe oito vozes no quarteto de cordas. Este caso é observado entre os compassos 84 e 88, com exceção do compasso 86, que, com o recurso dos harmônicos, surgem oito vozes numa escrita para quarteto de cordas (Figura 13). 
Consideramos esta movimentação do tema entre diferentes vozes como análoga ao procedimento de Haydn, no Quarteto de cordas $n$. I op. 33, que Rosen denominou de contraponto clássico (Figura 5). A única diferença é que Villa-Lobos não transforma o acompanhamento em tema e vice-versa. Aliás, esta ausência de acompanhamento reforça a hipótese de que o foco principal desta passagem é a exploração do timbre, que é uma característica marcante na música do século XX (Figura 13).
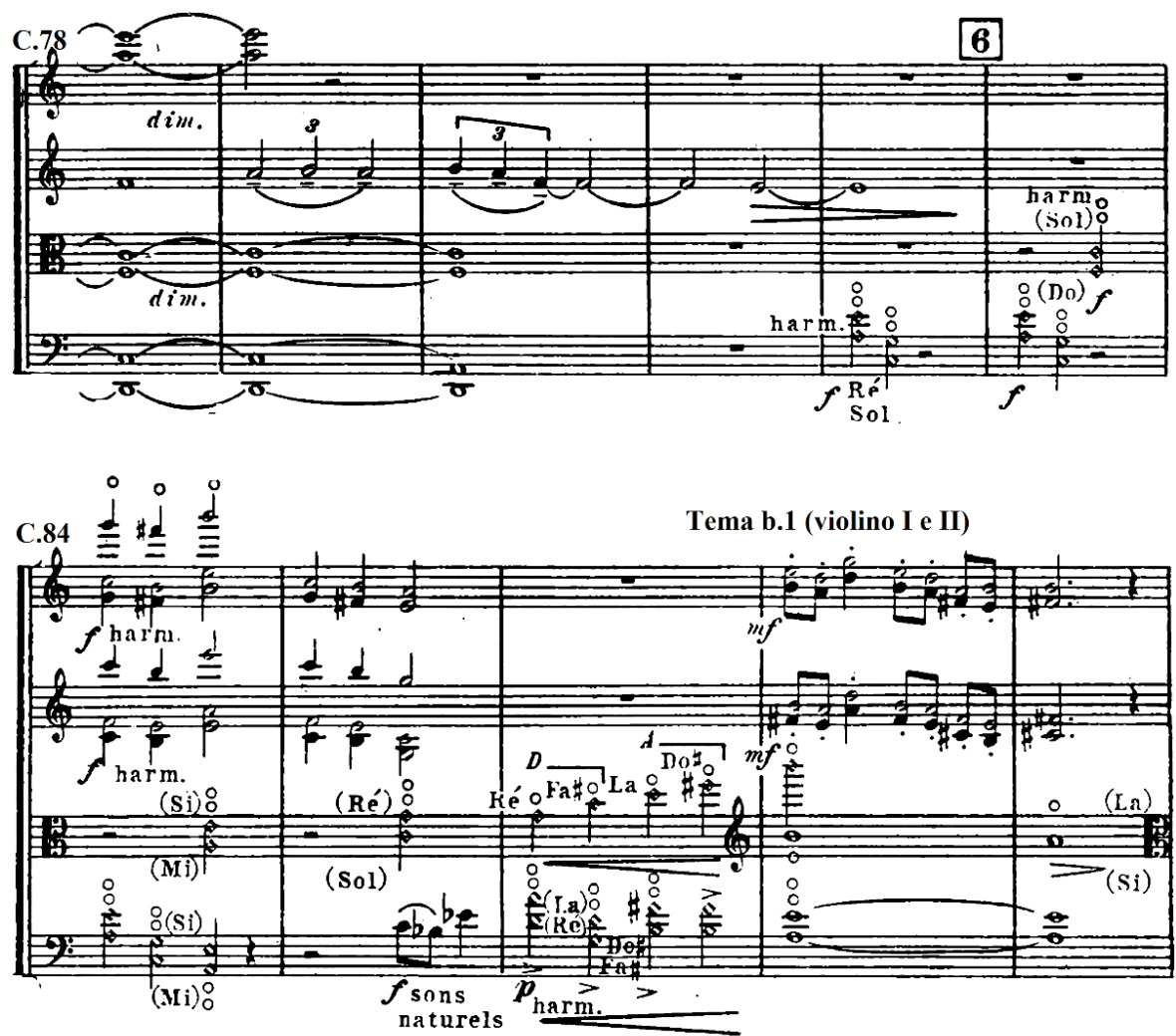

Figura 13: Quarteto de Cordas n. 3 de Villa-Lobos. Desenvolvimento. Fragmentação do tema cíclico (c) em diferentes timbres.

Assim sendo, salientamos a habilidade de Villa-Lobos em dialogar com o passado, e de modo sincrônico, contribuir para a construção 
da música do seu tempo, assim como outros compositores canônicos do século XX. A título de exemplo, em 1909 temos uma composição significativa que ressalta o timbre como um critério capital na música do século XX. Trata-se do terceiro movimento da Fünf Orchesterstücke op. 16, Farben, de Schoenberg. Em 1916, temos Villa-Lobos fracionando um tema em diferentes timbres (Figura 13). Quanto a este episódio, consideramos um caso muito parecido, o procedimento utilizado por Anton Webern (1883-1945) ao compor a Fuga Ricercata (1934-5), do qual o thema regium é fragmentado entre diferentes instrumentos (Figura 14). Escolhemos apenas estes dois exemplos de compositores consagrados da música do século XX, apenas para ressaltar que, apesar de Villa-Lobos não ter tido uma formação institucionalizada²!, ele tinha plena consciência do léxico da tradição musical assim como da poética vanguardista.

21 De acordo com Guérios (2003, p. 86), em 1904 Villa-Lobos se matriculou no Instituto Nacional de Música para estudar violoncelo. No entanto, este curso noturno foi extinto e após 1904. Como o próprio Villa-Lobos relata, sua iniciação musical ocorreu desde a infância: "Desde a mais tenra idade iniciei a vida musical, pelas mãos de meu pai, tocando um pequeno violoncelo... Aprendi, também, a tocar clarinete e era obrigado a discernir o gênero, estilo, caráter e origem das obras, como a declarar com presteza o nome da nota, dos sons ou ruídos que surgiam incidentalmente no momento, como, por exemplo, o guincho da roda de um bonde, o pio de um pássaro, a queda de um objeto de metal, etc. Pobre de mim quando não acertava..." (VILLA-LOBOS, 1969, [ 1957], pp. 98-99).

\section{9}

REV. TULHA, RIBEIRÃO PRETO, v. 6, n. 2, pp. 119-151, jul.-dez. 2020 


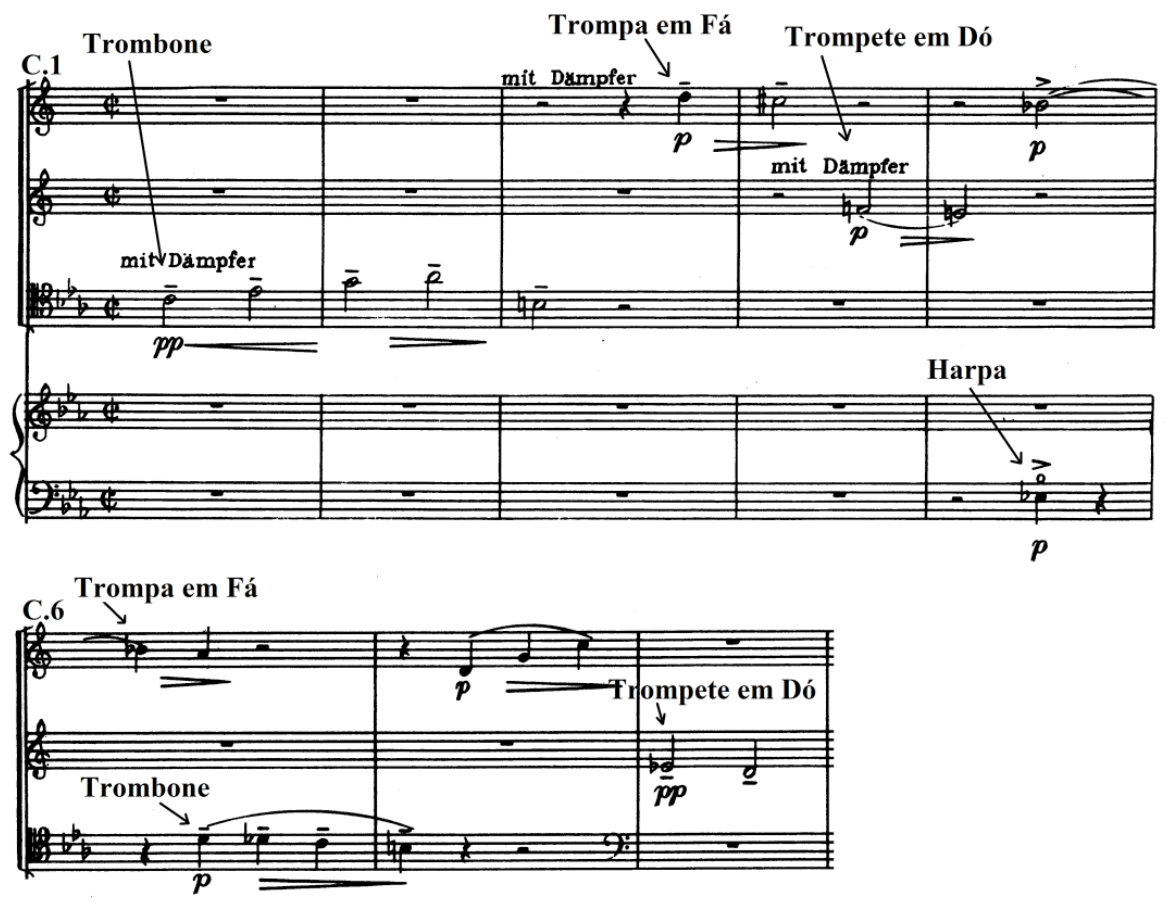

Figura 14: Fuga Ricercata de Anton Webern.

Thema regium fracionado entre diferentes instrumentos.

Entre os compassos 93 a 124, o tema b.l aparece de forma sucessiva, começando pelo instrumento mais grave até ao mais agudo (Figura 15). A partir deste momento até o final deste movimento, apresenta-se a "figuração de ostinato como fundo textural" da qual Salles (2009, p. 78) ilustra ser uma prática recorrente da música de Villa-Lobos. 
Obs. Tema b. 1

derivado do tema cíclico b
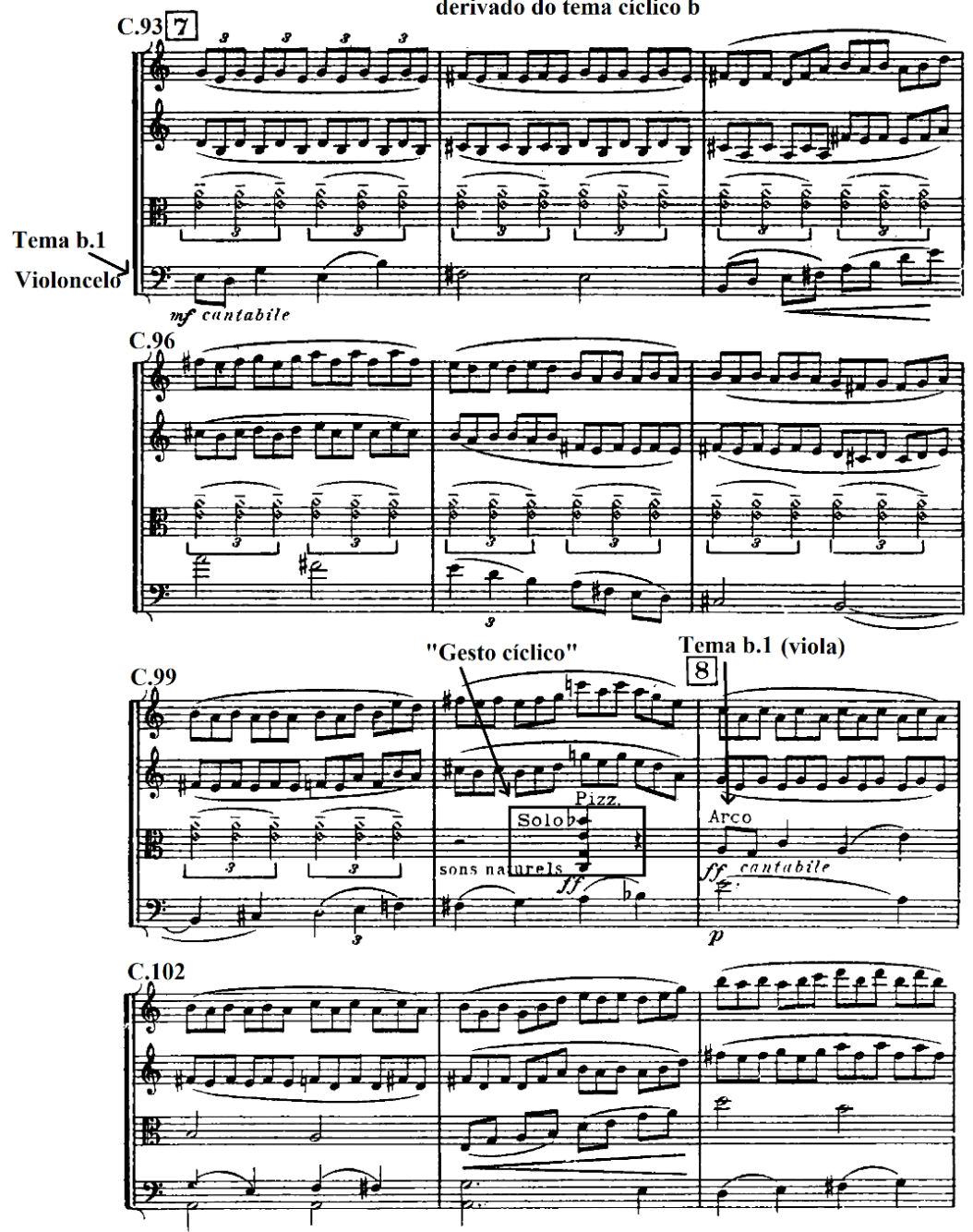

Tema b.1 (violino II)

Violino II Violino II

Figura 15: Quarteto de Cordas n. 3 de Villa-Lobos. Desenvolvimento. Tema b.l a partir do compasso 93. 
Como já observado por Salles (2017c, p. 433), no compasso 133 existe a superposição de temas nas vozes extremas, enquanto nas vozes intermediárias estão dispostas em ostinato (Figura 16).

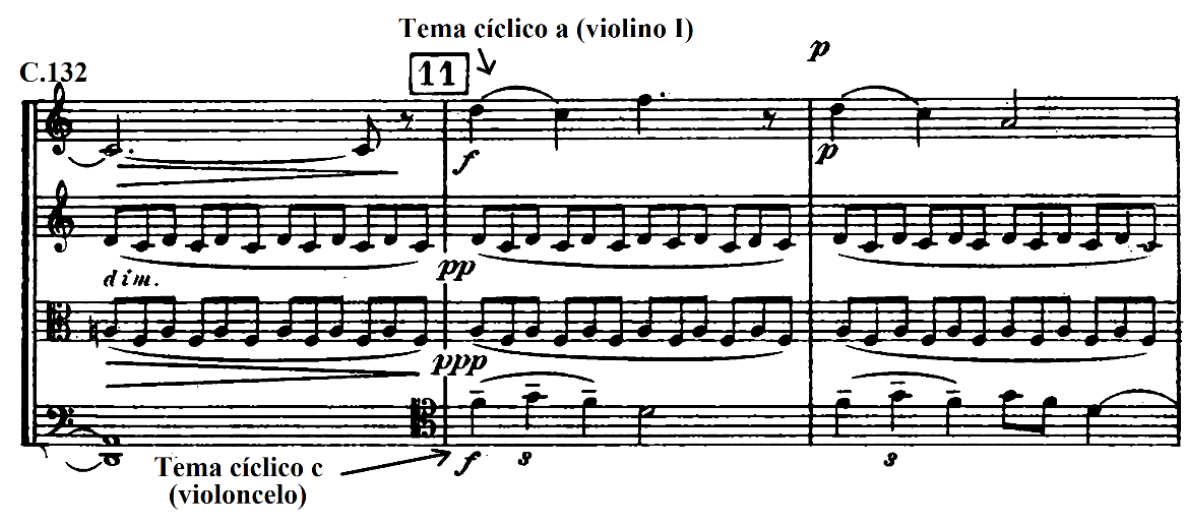

Figura 16: Quarteto de Cordas n. 3 de Villa-Lobos. Desenvolvimento. Superposição de temas. Compasso 133.

Entre os compassos 141 e 148, os temas continuam superpostos nas vozes extremas, porém ocorre uma inversão quanto aos instrumentos. O tema cíclico (c) passa a ser tocado pelo violino l e o tema cíclico (a) é disposto em quintas justas e tocado pelo violoncelo. Consideramos esta variação temática no tema cíclico (a), construída em quintas paralelas, uma característica da música do século XX, que se traduz numa tentativa de impedir qualquer senso de progressão tonal (Figura 17). De acordo com Kostka et al. (2013, p. 472) "Uma das mais antigas indicações da quebra com procedimentos tradicionais de progressão harmônica foi o uso do paralelismo na condução das vozes"22.

22 "One of the earliest indications of a break with traditional procedures of harmonic progression was the use of parallelism in the voice motion" (KOSTKA et al., 2013 p. 472) 


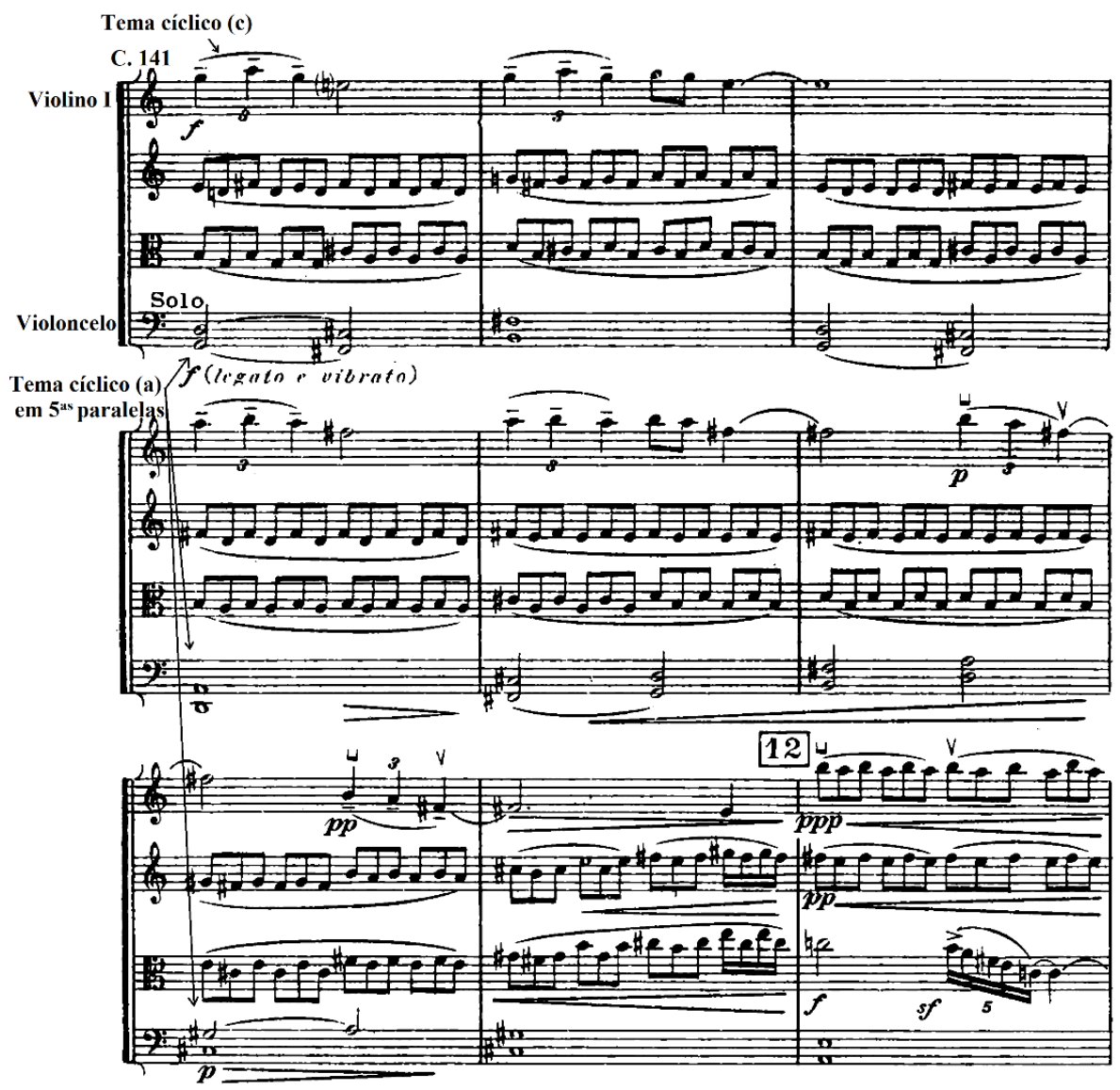

Figura 17: Quarteto de Cordas n. 3 de Villa-Lobos. Desenvolvimento. Superposição de temas.

Entre os compassos 153 e 171, o tema cíclico (c) reaparece com uma célula motívica ambígua, que tanto pode ser uma reminiscência do tema (a) como do tema (b), pois, como já comentado, estes dois temas possuem os mesmos intervalos iniciais: segunda maior e terça menor (Figura 18). 

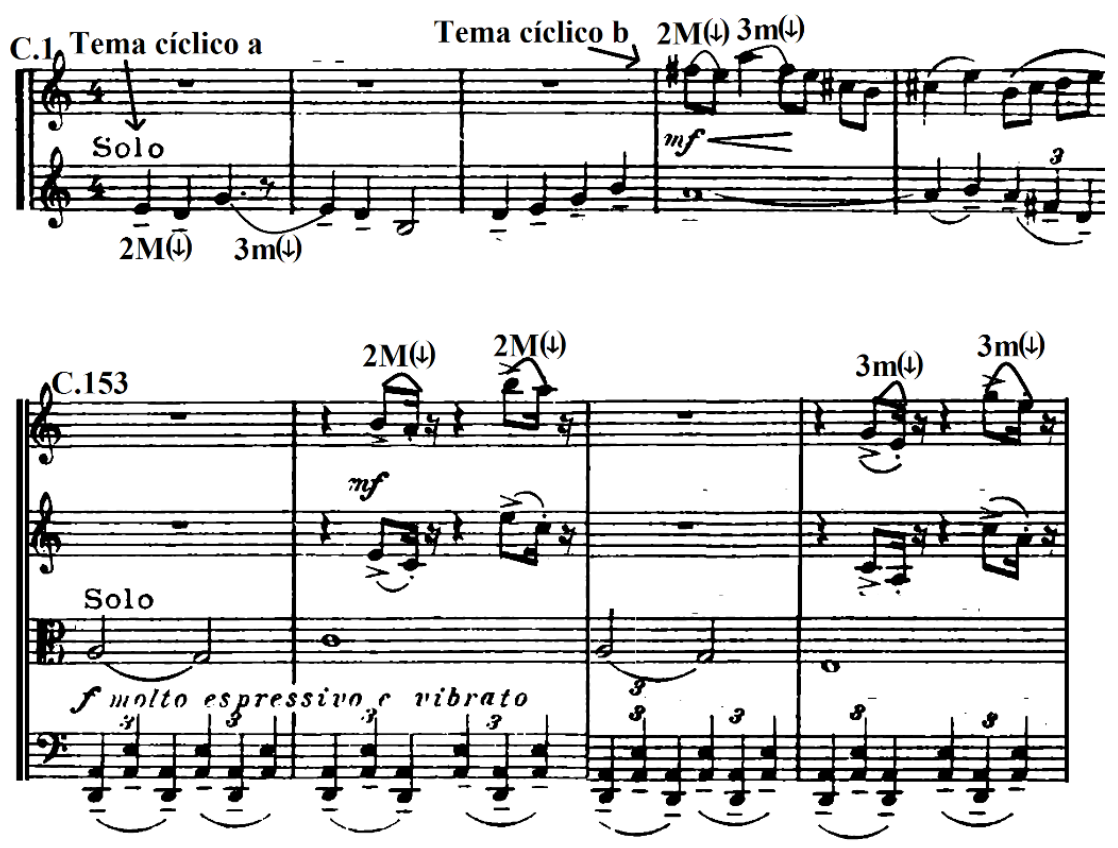

Figura 18: Quarteto de Cordas n. 3 de Villa-Lobos. Intervalos dos motivos dos temas (a) e (b).

início da recapitulação ocorre no compasso 172 com o retorno do tema cíclico (a) e com a mesma textura homofônica do primeiro compasso da exposição (Figura 19).

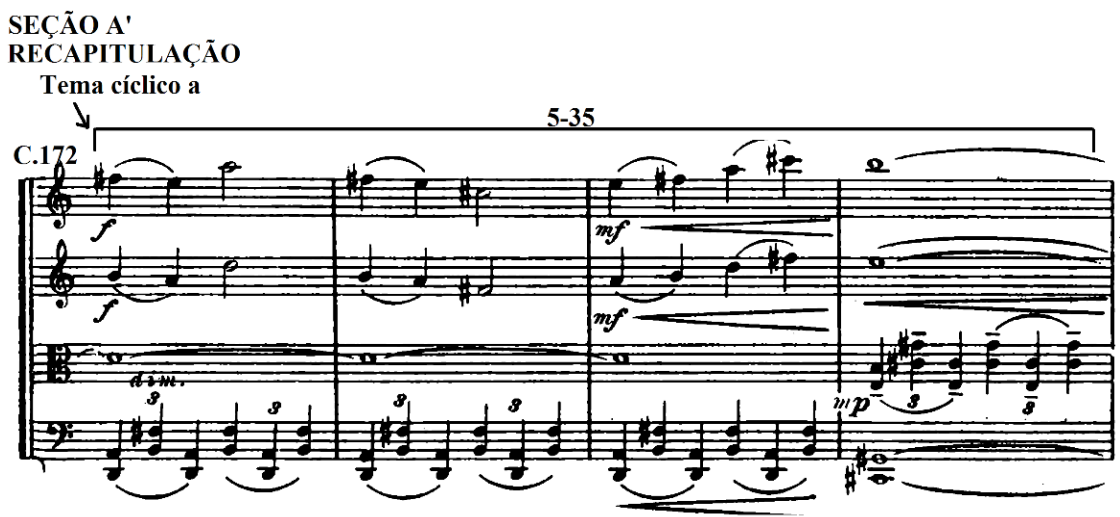

Figura 19: Quarteto de Cordas n. 3 de Villa-Lobos. Recapitulação. 
O tema cíclico (b) não é reexposto de forma literal, porém é possivel considerar que ele está implícito no tema cíclico (a) que, apesar de estar construido sobre a escala pentatônica CCA 5-35, está disposto com as mesmas primeiras seis notas do tema cíclico (b) da exposição e não apenas pelos mesmos intervalos como ocorreu anteriormente. Isto significa que o ritmo e a textura caracterizam explicitamente o tema cíclico (a), porém o tema cíclico (b) pode ser subentendido neste contexto por meio das notas idênticas ao primeiro pronunciamento realizado na exposição (Figura 20).

\section{REEXPOSIÇÃO \\ Tema cìclico b (violino I)}

\section{Tema cíclico a (violino I)}

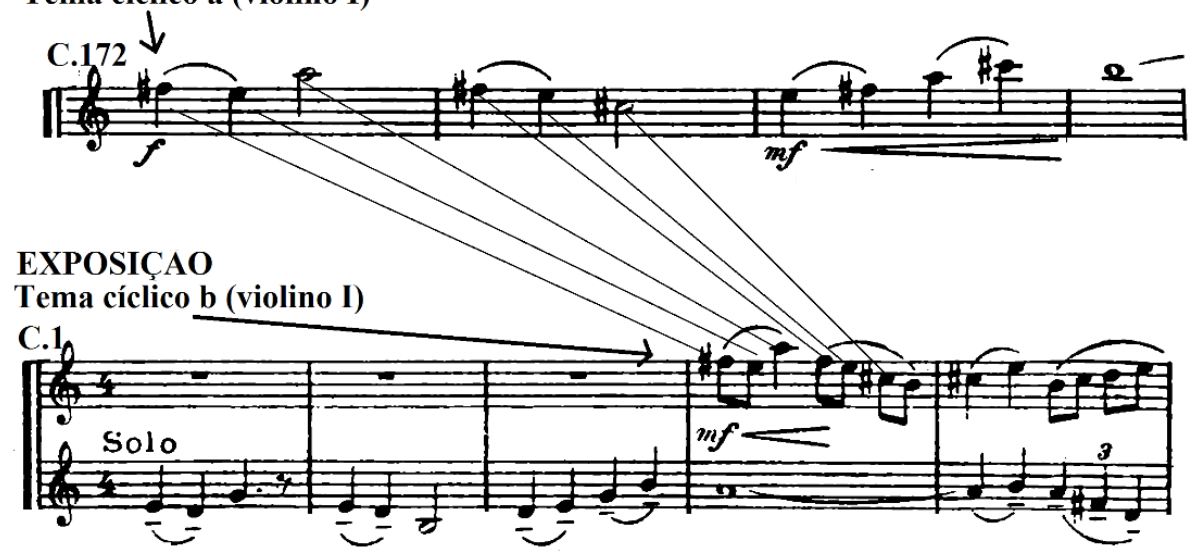

Figura 20: Quarteto de Cordas n. 3 de Villa-Lobos. Tema cíclico (a) e (b). Recapitulação e Exposição.

Este movimento é finalizado com o motivo principal do tema cíclico (c) no violoncelo (a partir do compasso 182) e no violino I (a partir do compasso 186) (Figura 21 ). 


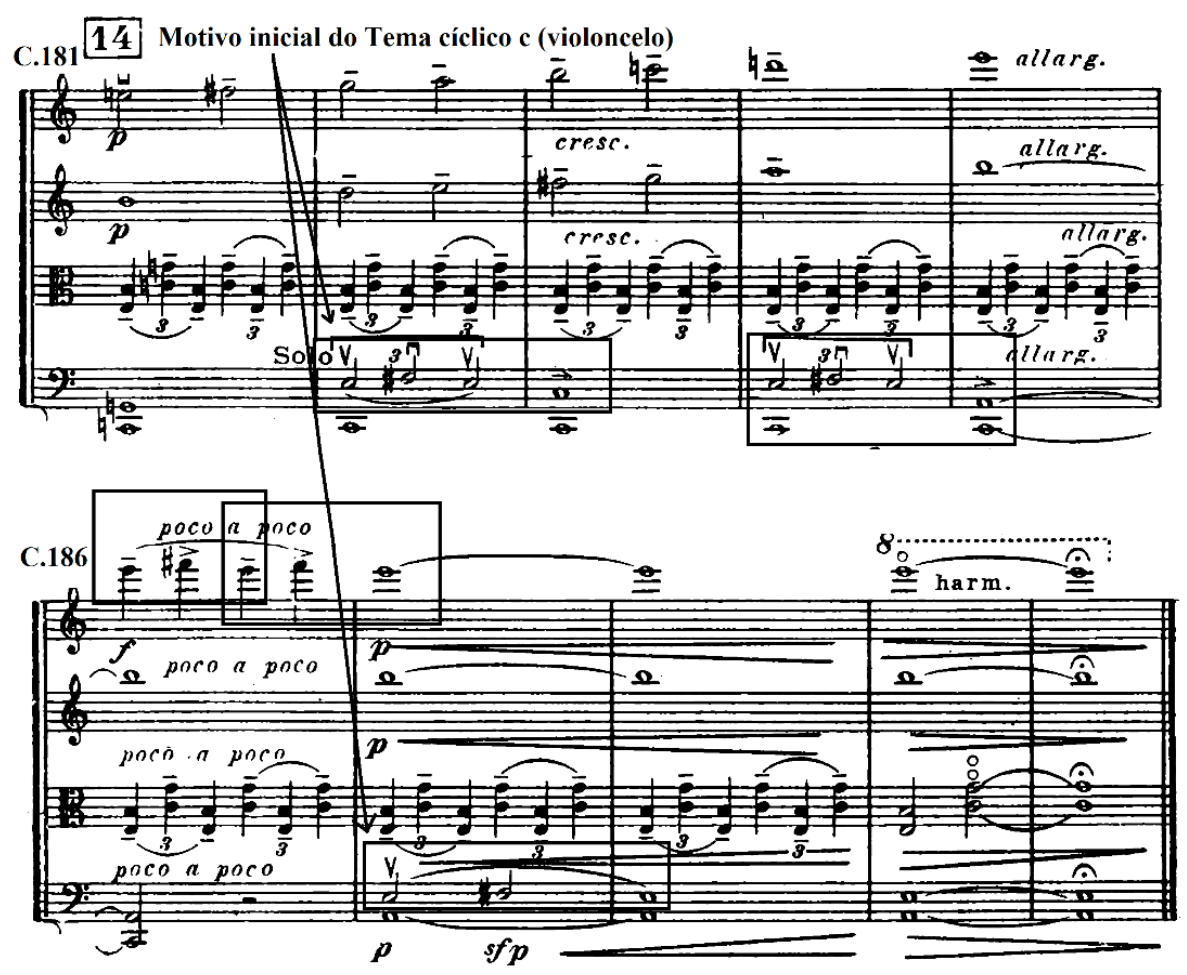

Figura 21: Quarteto de Cordas n. 3 de Villa-Lobos. Tema cíclico (c). Recapitulação. 


\section{Considerações Finais}

Villa-Lobos foi o compositor que produziu o maior número de quarteto de cordas, no âmbito da música brasileira. E no cenário internacional da música do século XX, em termos quantitativos, só está abaixo do compositor francês Darius Milhaud, que escreveu 18, ao passo que Villa-Lobos escreveu 17 quartetos. Este fato demonstra a competência de Villa-Lobos, uma vez que, em termos técnicos, este gênero representa um dos maiores desafios composicionais da música ocidental.

Por meio desta análise concisa, constatou-se que Villa-Lobos organizou o primeiro movimento do Quarteto de Cordas $n^{\circ} 3 \mathrm{em}$ três seções, conforme a estrutura da forma sonata (Exposição, Desenvolvimento e Recapitulação). Para elaborar esta estrutura numa composição não tonal, Villa-Lobos utilizou a manipulação dos conjuntos de classes de alturas (CCA) como referência às modulações do sistema tonal, inerentes à forma sonata clássica. Sendo assim, o início das Seções é marcado por meio da inversão do referencial escalar, como é possível rememorar no quadro abaixo (Quadro 1).

\begin{tabular}{|c|c|}
\hline EXPOSIÇAO & $\begin{array}{l}\text { O tema cíclico (a) permanece construído sobre } \\
\text { o CCA 5-35, enquanto o tema cíclico (b) } \\
\text { movimenta-se em outros referenciais escalares. }\end{array}$ \\
\hline DESENI & $\begin{array}{l}\text { O tema cíclico (a), que, durante a exposição, } \\
\text { sempre permaneceu estruturado no CCA 5-35, } \\
\text { abre a seção do desenvolvimento elaborado } \\
\text { pelo CCA 7-27. E o tema cíclico (b) passa a ser } \\
\text { construído pelo CCA } 5-35 \text { e possui as mesmas } \\
\text { primeiras seis notas da primeira instauração do } \\
\text { tema cíclico (a) na exposição: Mi-Re-Sol-Mi-Re- } \\
\text { Si. Sendo assim, o desenvolvimento é inaugurado } \\
\text { com a inversão CCA nos temas cíclicos (a) e (b) } \\
\text { em relação à seção anterior (Figura 7). }\end{array}$ \\
\hline RECAPITULAÇÃO & $\begin{array}{l}\text { Na recapitulação, as primeiras seis notas do tema } \\
\text { cíclico (a) são literalmente as mesmas primeiras } \\
\text { seis notas do tema cíclico (b) da exposição } \\
\text { (Fa\#-Mi-Lá-Fa\#-Mi-Do\#), porém edificado por } \\
\text { meio da textura homofônica do tema cíclico (a). } \\
\text { Desta forma, o início da recapitulação é marcado } \\
\text { pela inversão textural dos temas cíclicos (a) e (b). } \\
\text { (Figura 20). }\end{array}$ \\
\hline
\end{tabular}

Quadro 1: Primeiro movimento do Quarteto de Cordas n. 3 de Villa-Lobos. Entrada das seçōes. 
Por meio da fragmentação do tema entre timbres distintos (figura 13), Villa-Lobos inseriu a sonoridade do século XX, no gênero da música de câmara mais emblemático do classicismo musical europeu.

Portanto, esta sucinta análise é uma pequena contribuição para atestar a proficiência composicional de Villa-Lobos, ao adaptar um dos requintes formais da música ocidental do período clássico-romântico (forma sonata) para a música do século XX, no suprassumo do gênero do classicismo musical europeu (quarteto de cordas).

\section{Referências}

ALBUQUERQUE, Joel Miranda Bravo de. Simetria intervalar e rede de coleções: análise estrutural dos Choros $n^{\circ} 4$ e Choros $n^{10} 7$ de Heitor Villa-Lobos. 2014. Dissertação (Mestrado em Processos de Criação Musical) - Escola de Comunicações e Artes, Universidade de São Paulo, São Paulo, 2014. DOl:10.1 1606/D.27.2014.tde-02022015-144058. Acesso em: 22 jan. 2018.

ALBUQUERQUE, Joel Miranda Bravo de. Simetria na música póstonal. Rede de projeções por inversão. 2018. Tese (Doutorado em Musicologia) - Escola de Comunicações e Artes, Universidade de São Paulo, São Paulo, 20 18. doi: 10.1 1606/T.27.2018.tde-27 122018 - 104544. Acesso em: 23. out. 2020.

CANDÉ, Roland. Historia universal da música. Trad. Eduardo Brandão. São Paulo: Martins Fontes, 1994. I v.

COOK, Nicholas. A guide to musical analysis. New York: Oxford University Press, 1987. Reiprinted 2009.

ESTRELLA, Arnaldo. Os quartetos de cordas de Villa-Lobos. Rio de Janeiro: MEC, Museu Villa-Lobos, 1970.

FOURNIER, Bernard. Histoire du Quatuor a Cordes: de Haydn a Brahms. Paris: Librairie Arthème Fayard, 2000. I v. p. 1 1-33. Disponivel em: <http://www.bernard-fournier-quatuor.com/extraits/HdQ 1 Introductionoctobre2011.pdf>. Acesso em: 02 mai. 2018. 
CUÉRIOS, Paulo Renato. "Heitor Villa-Lobos e o ambiente artístico parisiense: convertendo-se em um músico brasileiro". Mana. 2003, vol.9, n. l, pp. $81-108$.

CREEN, Douglass. Form in tonal music: an introduction to analysis. New York: Schirmer G books, 1979.

Kostka, Stefan. PAYNE, Dorothy. ALMÉN, Byron. Tonal harmony: with an introduction to twentieth-century music. 7th ed. New York: McGraw-Hill, 2013.

KUHN, Thomas S. A estrutura das revoluções científicas. 9 ed. Trad. Beatriz Vianna Boeira e Nelson Boeira. São Paulo: Perspectiva, 2006.

HECEL, Georg. Curso de estética: o sistema das artes. $2^{\circ}$ edição. São Paulo: Martins Fontes, 2010.

MASSIN, Jean. MASSIN, Brigitte. História da Música Ocidental. Rio de Janeiro: Nova Fronteira, 1997.

MOORE, Douglas. Guia dos estilos musicais: do madrigal à música moderna. Trad. Teresa Louro Pérez. Lisboa: Edições 70, 2001.

PERLE, George. Serial Composition and Atonality: An Introduction to the Music of Schoenberg, Berg and Webern. Berkeley, California: University of California Press, 1991.

ROSEN, Charles. The classical style: Haydn, Mozart, Beethoven. New York: Norton, 1998.

Sonata forms. New York: Norton, c 1988.

SALLES, Paulo de Tarso. Organização harmônica no movimento final do Quarteto de Cordas no. 15 de Villa-Lobos. Anais do XVIII Congresso da ANPPOM. Salvador: UFBA, pp. 98-103, 2008.

Quarteto de Cordas n. 10 de VillaLobos: Densidade Temática e Releitura da Forma-Sonata. Anais do XX Congresso da ANPPOM. Florianópolis: UDESC, pp. 1608-1615, $2010 \mathrm{~b}$. 
“Haydn, segundo Villa-Lobos: uma Análise do Primeiro Movimento do Quarteto de Cordas n.7 de Villa-Lobos". Per Musi, Revista Acadêmica de Música, n. 25, jan-jun. Belo Horizonte: UFMG, pp. 27-38, 2012a.

"Quarteto de Cordas no. 2 de VillaLobos: Diálogo com a Forma Cíclica de Franck, Debussy e Ravel". Música Hodie, v. 12 n. I. Goiânia: UFG, pp. 25-43, 2012 b.

ORFEU, v.2, n. I, jul. de 2017. pp. 68 de 97

"O Quarteto de Cordas n.8 (1944) de Villa-Lobos: neoclassicismo e invenção". Revista Orfeu, v. 2 n. I. UDESC, pp. 68-97, 2017a.

Inventando uma tradição: os quartetos de Villa-Lobos. Libreto do Box com os CDs "Villa-Lobos - Quartetos de Cordas - Quarteto Bessler-Reis e Quarteto Amazônia”, São Paulo: Selo SESC, CDSS $0091 / 17,92 \mathrm{p}, 2017 \mathrm{~b}$.

A forma sonata nos quartetos de VillaLobos. In: Salles, Paulo de Tarso e Dudeque, Norton (Org.). Villa-Lobos, um compêndio: novos desafios interpretativos. Curitiba: Editora UFPR, $2017 \mathrm{c}$

TARASTI, Eero. Villa-Lobos the life and works 1887-1959. Jefferson, North Carolina: McFarland \& Company, 1995.

VILLA-LOBOS. Autobiografia. Presença de Villa-Lobos. Rio de Janeiro: MEC/Museu Villa-Lobos, 1969 [ 1957$].$

VISCONTI, Ciro. Simetria nos Estudos para violão de Villa-Lobos. Jundiaí: Paco Editorial, 2016. 


\section{Sobre a autora}

Regina Rocha é doutoranda em Música pela Universidade de São Paulo (ECA/USP), na área de Teoria e Análise Musical, sob orientação do Prof. Dr. Paulo de Tarso Salles. Mestra em Musicologia e bacharela em Regência pelo Instituto de Artes da Unesp. Concluiu o curso técnico em Música (piano) pela Escola Municipal de Música Maestro Fêgo Camargo (Taubaté/SP) e possui formação pedagógica em música pela Faculdade Mozarteum de São Paulo.

Atuou como regente assistente da Orquestra Filarmônica Jovem de Caieiras e regente convidada da Orquestra e Coral da Sociedade Pró Música Sacra de São Paulo. Atualmente é membro do Núcleo Caravelas e integra o Grupo de Pesquisa PAMVILLA (Perspectivas Analíticas para a Música de Villa-Lobos).

Recebido em 01/12/2020

Aprovado em 23/12/2020 